\title{
Construindo a Base de Dados de Teses, Dissertações e Monografias sobre Estudos Fronteiriços
}

\author{
Rafael Port da Rocha' \\ Adriana Dorfman" \\ Arthur Borba Colen Françall'
}

\section{RESUMO}

A construção de uma base de dados de teses, dissertações e monografias sobre Estudos Fronteiriços envolve definir a comunidade dos Estudos Fronteiriços brasileiros (com base nos diretórios e plataformas das agências de fomento); investigar os limites teóricos do termo fronteira (centralmente, a fronteira territorial interestatal, emergindo estudos ligados à migração e às fraturas urbanas); estabelecer o recorte temporal da pesquisa (entre 2000 e 2014, com atualizações anuais); elencar universidades prioritárias (UFRGS, UFGD, UFRJ, UFMS e UNIPAMPA), entre outras decisões. Em suma, trata-se de definir como representar teses, dissertações e monografias: como localizá-los nos repositórios, quais dados selecionar, como registrar esses metadados etc. Os propósitos da base de dados organizada pelo projeto Unbral Fronteira (oferecer referências de estudos sobre as fronteiras brasileiras para ciências espacializadas) demandam esforços para a inserção de informações georreferenciáveis, levando à organização

I Professor do Departamento de Ciências da Informação da UFRGS.

E-mail: rafael.rocha@ufrgs.br

II Professora do Departamento de Geografia e do Programa de Pós-Graduação em Geografia da Universidade Federal do Rio Grande do Sul. Coordenadora do projeto Unbral Fronteiras - Portal de Acesso Aberto das Universidades Brasileiras sobre Limites e Fronteiras. Líder do GREFIT - Grupo de Pesquisas Espaço Fronteira Informação Tecnologia. E-mail: adriana.dorfman@ufrgs.br

III Bacharel em Relações Internacionais pela Universidade Federal do Rio Grande do Sul, Membro da equipe de pesquisa do projeto Unbral Fronteiras - Portal de Acesso Aberto das Universidades Brasileiras sobre Limites e Fronteiras e do GREFIT - Grupo de Pesquisas Espaço Fronteira Informação Tecnologia.

E-mail: arthurlunabcf@outlook.com 
de um vocabulário consensuado, referido nos códigos do IBGE para países, municípios e estados e considerando a regionalização proposta no Programa de Desenvolvimento da Faixa de Fronteira. A complexidade do projeto requer trabalho colaborativo no apoio ao desenvolvimento da base de dados, empregando-se para isso a MediaWiki, que permite comunicar, coordenar e cooperar. O projeto potencializa recursos quantitativos e qualitativos, permitindo estabelecer práticas claras para a construção do Portal Unbral Fronteiras.

PALAVRAS-CHAVE: Base de Dados, Portal Unbral Fronteiras, Estudos Fronteiriços, Metodologia, Georreferenciamento

\section{INTRODUÇÃO}

O texto que segue apresenta a arquitetura do Unbral Fronteiras - Portal de Acesso Aberto das Universidades Brasileiras sobre Fronteiras e Limites. Abordamos aqui a concepção do objeto a ser investigado, o problema de sua modelização e as estratégias para a consecução de tais objetivos.

Ainda que se trate, na maior parte do tempo, da descrição de operações da Ciência da Informação, é nossa intenção tornar o texto e a discussão relevantes para os Estudos Fronteiriços (EF). O esforço necessário para criar enquadramentos para os objetos concretos que nos interessam (a fronteira e os trabalhos sobre ela) metaforiza a passagem contemporânea que nos leva da fronteira territorial (ainda que em diálogo com a representação cartográfica) para as fronteiridades baseadas em bancos de dados que se disseminam por todos pontos do território (AMILHAT-SZARY; GIRAUT, 2015).

\section{CARACTERÍSTICAS}

As teses, dissertações e monografias (TDM) foram escolhidas para comporem a primeira coleção do Unbral Fronteiras em sua versão operacional. As TDM são exemplares da formação de 
cada pesquisador. Além disso, elas representam bastante bem o modelo de institucionalização da ciência, especialmente no nível da pós-graduação, pois a formação dos pesquisadores é, através delas, identificada com programas, disciplinas, escolas e temas, com genealogias teóricas, explicitando ainda lugar e ano de conclusão. Assim, esses documentos são capazes de representar os agentes, os conteúdos e as estruturas dos campos científicos contemporâneos.

Desta maneira, para descrever os Estudos Fronteiriços e para oferecer aos usuários do Portal Unbral Fronteiras um quadro do que tem sido produzido no campo, partimos para a identificação, descrição e reunião de teses, dissertações e monografias em uma base de dados.

Ao circunscrever o campo dos Estudos Fronteiriços caminhamos para apoiar a comunidade na estruturação de seu diálogo interno, facilitando o acesso à produção científica através da coleta e normatização dos trabalhos. Além disso, a base de dados permite análises qualitativas e quantitativas da produção de teses, dissertações e monografias em Estudos Fronteiriços, revelando os principais assuntos, os locais de fronteira abordados, os produtores de destaque, facilitando ainda o cruzamento dessas informações.

Outra característica importante da base que construímos é permitir estudos georreferenciados: para ciências dedicadas a objetos territoriais, no caso, a fronteira, a espacialização é amplamente explicativa de padrões temáticos e de outras características da produção científica.

Os primeiros desafios da construção da base de dados de teses, dissertações e monografias em Estudos Fronteiriços foram delimitar o conceito de fronteira e circunscrever o campo dos Estudos Fronteiriços. Isso se fez através da identificação das instituições, de seus pesquisadores e da interpretação corrente sobre o conceito. Instituições e pesquisadores foram listados a partir 
da Plataforma Sucupira da Coordenação de Aperfeiçoamento de Pessoal de Nível Superior (CAPES). A Plataforma Sucupira informa sobre os programas de pós-graduação, as áreas de concentração, as linhas de pesquisa e as pessoas envolvidas nos diferentes campos da ciência brasileira (CAPES, 2016). Já a interpretação corrente sobre o termo "fronteira" foi estabelecida com auxílio de um questionário para Experts em Estudos Fronteiriços, descrito no Anuário Unbral 2014 (DORFMAN; MONTE MEZZO; FRANÇA, 2015). As seções "Os limites teóricos do termo fronteira" e "A comunidade dos Estudos Fronteiriços brasileiros" apresentam e discutem, respectivamente, questões de circunscrição do termo fronteira e do campo de estudos a ela dedicado.

A tarefa que empreendemos a seguir foi identificar as fontes de informação, isto é, as bases de dados em que se encontram as teses, dissertações e monografias: realizamos um estudo dos repositórios das universidades. Tal estudo consistiu na listagem de todas as universidades federais, na localização de seus repositórios, na descrição da estrutura desses repositórios e na contagem dos itens pertinentes para o projeto. Relacionando 1. a produção em Estudos Fronteiriços no conjunto de instituições identificado com 2. a estrutura de seus repositórios, definimos universidades prioritárias, movimento descrito no item "Estudo para definição das fontes de informação: universidades prioritárias".

Os repositórios consultados são fontes multidisciplinares, sendo necessário selecionar neles a produção em Estudos Fronteiriços. Outra questão é que sua indexação é feita através de termos nãoespecializados, já que o termo "fronteira" é usado em diferentes contextos, muitos dos quais não se relacionam àqueles sentidos atribuídos pelos "fronteirólogos". Isso demanda por esforços em selecionar, nessas coleções, aquelas teses, dissertações e monografias sobre Estudos Fronteiriços, com base na busca por palavras-chave e na análise do conteúdo do item, isto é, checando sua aderência aos limites teóricos estabelecidos através deste 
projeto em seus esforços em delimitar o campo em colaboração com a comunidade.

Por tratar-se de um esforço de convergência de fontes, buscamos construir uma coleção integrável com outras coleções de Estudos Fronteiriços, optando pela utilização de padrões internacionais de representação da informação. No nosso caso, o consenso foi por usar o padrão Dublin Core.

Registrar os itens na base passa por uma padronização do dado, visto que nomes de autores, orientadores, programas etc. aparecem em várias formas de codificação de informações (são escritos de várias maneiras) nas diferentes fontes. Assim, foi necessário estabelecer um padrão, permitindo que os dados possam ser consolidados e analisados, sempre respeitando a informação original. Essas escolhas são detalhadas na seção "A descrição dos itens".

Registrar os itens passa também por produzir novas informações, visto que desejamos organizar as publicações por local de produção e tópico espacial, com vocabulários controlados e padronizados (códigos IBGE para municípios e países), a fim de espacializar os metadados e as coleções. O registro levou em consideração a regionalização em uso no campo dos Estudos Fronteiriços brasileiros, contemplando atributos espaciais tais como país, arco, estado, municípios e classificação urbana (cidadegêmea, na linha, na faixa de fronteira), gerando valores a partir do código IBGE e de tabelas de correlação. Na seção "A expressão espacial dos itens" são relatados os estudos realizados para espacialização da coleção. Com informações espaciais consistentes, torna-se possível representar em interfaces cartográficas o local de publicação, tópicos espaciais e regionalização em uso nas fronteiras brasileiras.

A produção de dados sobre os períodos tematizados em cada tese, dissertação ou monografia permite também analisar de que 
períodos históricos a produção em Estudos Fronteiriços tem tratado, conforme discutimos em "Indexando períodos históricos".

Nas seções sobre "A coleta de dados" e sobre a construção do "Repositório de dados" detalhamos os procedimentos de alimentação do banco de dados. Finalizamos este texto discutindo as vantagens do "Trabalho colaborativo no apoio ao desenvolvimento da base de dados", especialmente num projeto interdisciplinar e multissituado e avançando algumas "Conclusões" sobre a construção da base de dados georreferenciada de teses, dissertações e monografias sobre Estudos Fronteiriços, a BD de TDM em EF ou, mais simplesmente, o Unbral Fronteiras.

\title{
A COMUNIDADE DOS ESTUDOS FRONTEIRIÇOS BRASILEIROS
}

Em 2014 realizamos um levantamento no Diretório de Grupos de Pesquisa (DGP) e na Plataforma Lattes do Conselho Nacional de Desenvolvimento Científico e Tecnológico (CNPq) para identificar pesquisadores dedicados ao estudo das fronteiras. Segundo informação disponível na página institucional

\begin{abstract}
O Diretório dos Grupos de Pesquisa no Brasil é um inventário dos grupos em atividade no país. Os recursos humanos constituintes dos grupos, as linhas de pesquisa e os setores de atividade envolvidos, as especialidades do conhecimento, a produção científica, tecnológica e artística e os padrões de interação com o setor produtivo são algumas das informações contidas no Diretório. Os grupos estão localizados em instituições de ensino superior, institutos de pesquisa, etc. As informações individuais dos participantes dos grupos são extraídas dos seus Currículos Lattes (CNPQ, 2016).
\end{abstract}

No DGP, buscamos os membros de grupos de pesquisa cujo nome, linha de pesquisa ou palavras-chave contivesse a palavra "fronteira". Foram listados 182 pesquisadores. Seus endereços 
de e-mail foram pesquisados na Plataforma Lattes. Questionários foram enviados a esses endereços, sendo respondidos por 94 ou $52 \%$ dos pesquisadores consultados.

Três são as categorias passíveis de análise sobre a comunidade identificada: sua ocupação, o estado e o município em que estão baseados. Professores, docentes, professores aposentados (34), geógrafos (10), antropólogos (4), arquitetos e urbanistas (3) e estudantes (3) foram ocupações citadas mais de uma vez (com ocorrência maior que 1). Concluímos que a multidisciplinaridade é marcante, confirmando que a fronteira é um objeto transverso que comporta análise geográficas ou não geográficas.

Rio Grande do Sul (25), Mato Grosso do Sul (10), Paraná (5), Rio de Janeiro (5), Amapá (3), Roraima (3), Amazonas (2) e São Paulo (2) foram nomeados como estados de residência dos pesquisadores (>1). É interessante observar que a imensa maioria dos pesquisadores está em estados fronteiriços. Isso explica-se não só pela provocação do objeto, presente nessas regiões, mas também por questões estruturais e políticas. Dados os recursos limitados, os pesquisadores tendem a dedicar-se a objetos próximos de suas universidades, além de serem impelidos a estudar suas regiões para promover o desenvolvimento das mesmas. No entanto, a maioria dos pesquisadores não se encontra em cidades fronteiriças, e isso se explica pela situação dos centros produtores de pesquisas, concentrados nas capitais e cidades médias.

O detalhamento desse estudo pode ser encontrado em Dorfman, Monte Mezzo e França (2015).

\section{OS LIMITES TEÓRICOS DO TERMO FRONTEIRA}

Para a delimitação do campo dos Estudos Fronteiriços, a equipe do Unbral Fronteiras realizou um questionário com a comunidade acadêmica acerca do objeto científico 'fronteira' e seus contornos. O resultado detalhado pode ser encontrado em nosso Anuário 2014 
(DORFMAN, 2015). Conforme já publicado também na página do projeto (PORTAL UNBRAL FRONTEIRAS, 2016) e de forma sintética, os seguintes estudos são considerados para o Unbral Fronteiras:

- Estudos ligados a fronteiras internacionais

- Estudos relacionados a limites espaciais administrativos não-internacionais;

- Estudos relacionados a limites espaciais nãoadministrativos;

- Estudos relacionados a frentes pioneiras, frentes de expansão, fronteiras agrícolas etc. (frontiers);

- Estudos ligados a "fronteiras naturais" (rios, montanhas, serras etc.) que demarcam limites internacionais, ainda que não se refiram diretamente ao limite internacional;

- Estudos relacionados a aspectos físicos (geomorfológicos, climatológicos, hidrológicos etc.) em lugares situados na região fronteiriça

- Estudos relacionados a aspectos históricos (arqueológicos, povoamento, folclore etc.) de lugares atualmente situados na região fronteiriça, ainda que não abordem a construção do limite internacional;

- Estudos relacionados a questões étnicas e culturais (indígenas, identidades, produção artística etc.) em lugares situados na fronteira, ainda que não se refiram diretamente ao limite internacional;

- Estudos regionais de espaços como municípios, estados, regiões etc., que contém uma seção ou capítulo sobre a fronteira sem, no entanto, abordarem centralmente a região fronteiriça; 
- $\quad$ Estudos sociais que tematizam a cultura, a história, ou a formação territorial de espaços (estados, regiões, países etc.) que citam a região de fronteira sem abordarem centralmente questões fronteiriças;

- Estudos econômicos que tematizam o turismo, a indústria, as infraestruturas de espaços como estados, regiões, países etc., que citam a região de fronteira sem abordarem centralmente a região fronteiriça;

- Estudos que tematizam Migrações Internacionais, mesmo que não se refiram diretamente à região fronteiriça (bolivianos em São Paulo, trabalhadores haitianos em Caxias do Sul, catarinenses nos Estados Unidos etc);

- Estudos relacionados ao Planejamento Territorial, reestruturação de espaços rurais, desenvolvimento, sustentabilidade rural e regional etc. em lugares situados na fronteira, ainda que não se refiram a questões fronteiriças;

- Estudos de Comércio Internacional (políticas comerciais, fluxos de importação e exportação, movimentos financeiros internacionais etc) mesmo que não se refiram diretamente a questões fronteiriças;

- Estudos de Relações Internacionais com viés territorial (política externa brasileira, política internacional, América Latina etc.), mesmo que não se refiram diretamente a questões fronteiriças;

- Estudos relacionados à Integração Regional com viés territorial (blocos econômicos, Mercosul, Alca, IIRSA etc.), mesmo que não se refiram diretamente à região fronteiriça;

- Estudos relacionados à Defesa e Segurança com viés territorial (inteligência, geopolítica, estudos estratégicos, Estado e Segurança Internacional etc), mesmo que não se refiram diretamente à região fronteiriça. 
A figura 1, ao lado, sintetiza os resultados do questionário, mostrando os temas centrais e periféricos do estudo das fronteiras no Brasil.

\section{RECORTE TEMPORAL DA PESQUISA}

Os itens pesquisados na coleção Teses, Dissertações e Monografias estão compreendidos entre 2000 e 2014. A data inicial foi escolhida tomando em consideração a organização de repositórios institucionais em que encontrar informação consistente.

A data final busca estabelecer uma rotina na varredura dos repositórios, a ser realizada periodicamente. Alguns trabalhos demoram a ser inseridos nas bases institucionais, mas consideramos que todos os trabalhos produzidos em 2014 já estão publicados. Na sequência do projeto, atualizações serão realizadas, através do retorno às bases de dados das universidades.

\section{ESTUDO PARA DEFINIÇÃO DAS FONTES DE INFORMAÇÃO: UNIVERSIDADES PRIORITÁRIAS}

A coleta das Teses e Dissertações que viriam a formar a "Coleção TDM" do Portal Unbral Fronteiras precisava estabelecer prioridades. Essas prioridades envolviam a escolha das universidades que teriam seus repositórios varridos primeiramente. As demais universidades seriam analisadas posteriormente, ora através dos repositórios institucionais, ora de maneira indireta, através da Biblioteca Brasileira de Teses e Dissertações (BDTD).

Sendo um projeto com financiamento público e federal, privilegiamos as instituições de ensino com as mesmas características. Cinco foram as universidades definidas como prioritárias: Universidade Federal do Rio Grande do Sul (UFRGS), Universidade Federal do Pampa (UNIPAMPA), Universidade Federal do Rio de Janeiro (UFRJ), Universidade Federal de Mato Grosso 
Anuário Unbral das Fronteiras Brasileiras 2015

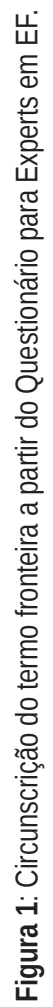

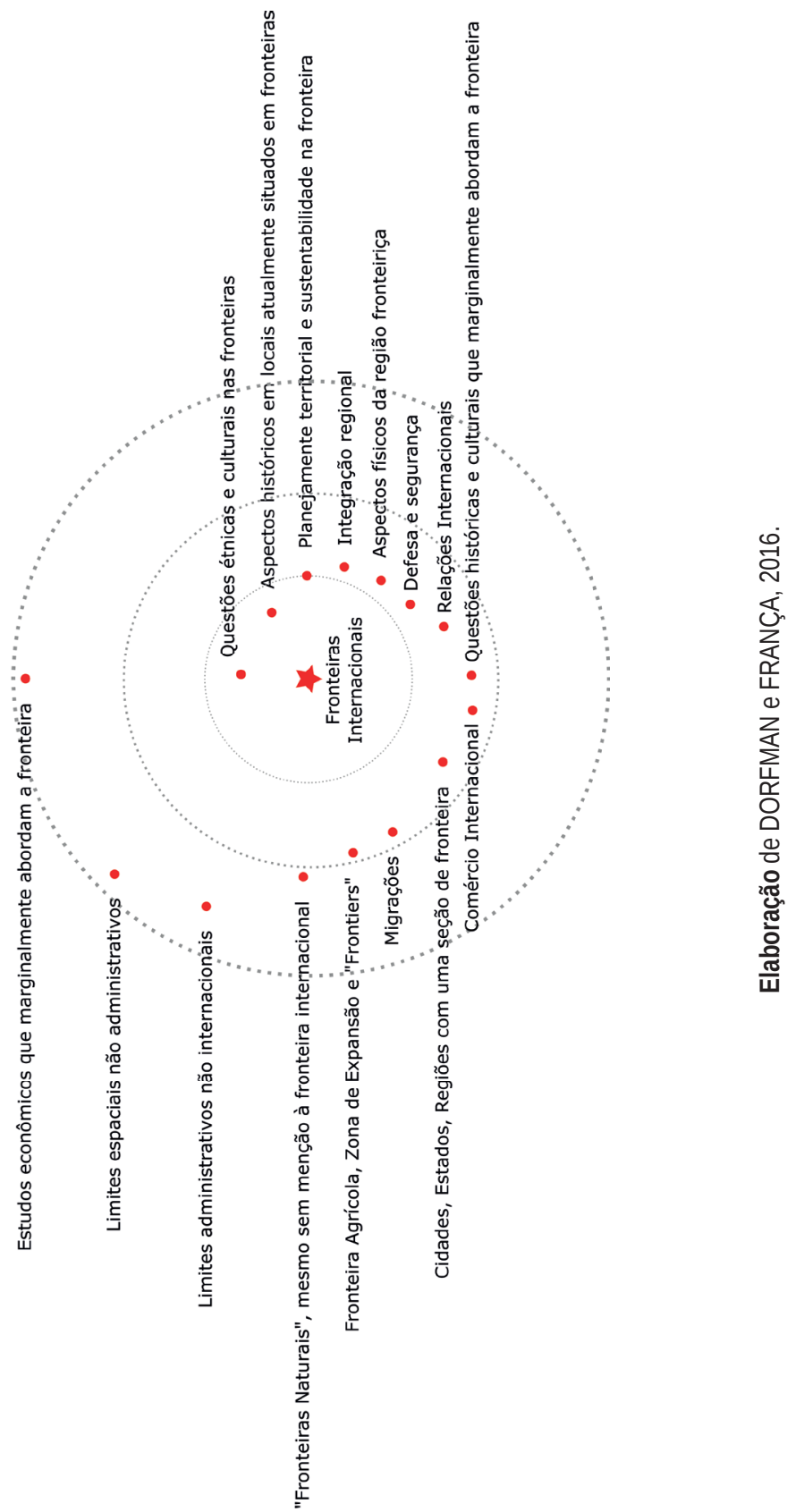


do Sul (UFMS) e Universidade Federal da Grande Dourados (UFGD). Essas cinco instituições foram selecionadas tomando em consideração (1) ser a instituição que abriga o projeto (UFRGS); (2) instituições fortemente ligadas aos Estudos Fronteiriços brasileiros (UNIPAMPA, UFRJ, UFMS, UFGD), como demonstram o (3) número de linhas de pesquisa relacionadas ao tema que se abrigam nessas instituições.

No Diretório de Grupos de Pesquisa do CNPq, a busca por linhas com a palavra-chave "fronteira" retorna 313 resultados. Analisando essas 313 ocorrências, excluímos 33 linhas - em geral ligadas à Matemática ou à Química - que não se relacionavam com fronteiras territoriais, ou que apresentavam resultados inconsistentes. Assim, temos 280 linhas de pesquisa dedicadas ainda que não centralmente - aos Estudos Fronteiriços. A lista de linhas de pesquisa consideradas está no Apêndice I.

Uma cartografia da distribuição das 280 linhas de pesquisa ligadas aos EF foi construída. O mapa que segue expressa, por estado, tal distribuição (figura 2).

Dorfman e França (2016), ao analisarem a distribuição acima, esclarecem quais são as universidades que se sobressaem:

O Mato Grosso do Sul destaca-se com 44 linhas de pesquisa dedicadas ao tema, em especial na UFMS (27) e na UFGD (12 linhas). O Rio Grande do Sul (UNIPAMPA, 14 linhas; UFRGS, sete), o Paraná (UNIOESTE, 12 linhas, UNILA, oito, UEM, seis) e o Rio de Janeiro (UFF, seis; UFRJ, cinco e UERJ, cinco linhas de pesquisa) têm expressiva produção. Amapá (14 linhas, todas na UNIFAP), Mato Grosso (14 linhas, sendo seis na UFMT), Roraima (11 linhas na UFRR); São Paulo (UNICAMP, cinco linhas, USP, quatro) e Pará (especialmente a UFPA, com nove linhas de pesquisa) também são importantes nesse panorama (p. 71). 
Figura 2: Brasil - A pesquisa em Estudos Fronteiriços (linhas de pesquisa com a palavra-chave "fronteira" por estado e universidades de destaque).

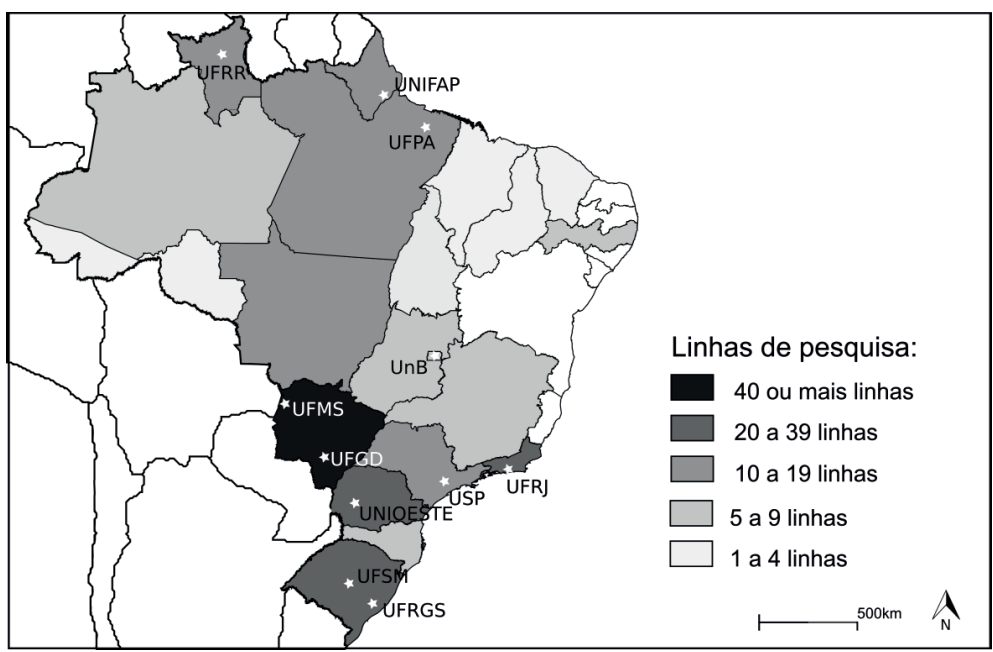

Fonte: Elaboração de DORFMAN e FRANÇA a partir de dados do DGP CNPq (2015).

Sendo assim, concluído o trabalho de coleta das cinco instituições prioritárias (UFRGS, UNIPAMPA, UFRJ, UFGD e UFMS), uma segunda leva de buscas e coletas em repositórios institucionais foi feita, com as universidades que se destacaram dado o grande número de linhas de pesquisa. O segundo grupo contém a Universidade Federal de Roraima (UFRR), a Universidade Federal do Amapá (UNIFAP), a Universidade Federal do Pará (UFPA), a Universidade Federal Fluminense (UFF), a Universidade Federal do Mato Grosso (UFMT), a Universidade Federal da Integração Latino-Americana (UNILA), a Universidade de Brasília (UnB), a Universidade de São Paulo (USP), a Universidade Estadual do Oeste do Paraná (Unioeste) e a Universidade Estadual de Maringá (UEM) e Universidade Federal de Santa Maria (UFSM), e também 
tem sua coleta feita de forma direta em seus repositórios. O restante das universidades públicas brasileiras será feito em um próximo momento, via BDTD.

Cabe citar que não há correspondência exata entre o número de linhas de pesquisa e o conteúdo dos repositórios de teses, dissertações e monografias, pois a instalação de programas de pós-graduação demanda mais tempo e maior esforço institucional do que a criação e certificação de uma linha de pesquisa.

\section{UMA NOTA SOBRE AS MONOGRAFIAS}

A coleção Teses, Dissertações e Monografias se compromete a fornecer teses e dissertações defendidas em instituições de ensino superior no Brasil. A coleta se faz segundo instituição. As monografias serão coletadas apenas na UNIPAMPA, pois a instituição firmou termo de cooperação com o Unbral Fronteiras (publicado no D.O.U. em 13/02/2015). Os dados coletados pela pesquisadora Thais Leobeth no campus Sant'Ana do Livramento da UNIPAMPA estão disponíveis no Portal Unbral Fronteiras, mas a íntegra dos documentos não foi publicada, em respeito aos direitos e diretrizes preconizados pela Iniciativa de Budapeste.

\section{A DESCRIÇÃO DOS ITENS}

A descrição dos itens envolve a definição de um esquema de metadados, isto é, a definição dos elementos necessários para descrever cada item, das regras para uso de cada elemento e para a codificação dos valores desses elementos (NISO, 2004). Um requisito importante é o uso de esquemas padronizados, pois isso facilita troca (interoperabilidade) desses registros com outros ambientes (bases de dados, buscadores, etc.).

Dublin Core (DC) foi o esquema de metadados adotado no Portal Unbral Fronteiras, pois o mesmo é amplamente usado em 
repositórios e buscadores na web (WEIBEL, 1995). O DC também foi definido como esquema de representação de metadados obrigatório a ser usado pelo padrão de interoperabilidade OAI-PMH. OAI-PMH é um protocolo padrão para promover a interoperabilidade entre arquivos abertos. Através do uso desse protocolo, várias bases de dados podem ser reunidas em torno de um portal de busca (MARCONDES; SAYÃO, 2002). Segundo Marcondes e Sayão (2002),

Informação em ciência e tecnologia livre na Internet, associada ao conjunto de metodologias colocadas à disposição da comunidade acadêmica pela Open Archive Initiative (OAI), abrem grandes possibilidades para os sistemas de informação que se dispuserem a avaliar com espírito criativo as oportunidades oferecidas por estas metodologias. Uma série de novos serviços baseados em reuso de metadados pode ser concebida, incluindo redes cooperativas e sistemas de informação regionais. O conjunto de metodologias OAI PMH - protocolo de coleta automática de metadados - é um protocolo de fácil implementação.

Sem dúvida, nosso projeto busca oferecer esses novos serviços com base no estabelecimento de cooperação. Para atender aos requisitos de interoperabilidade, optamos por qualificar o Dublin Core através da construção de um perfil de aplicação. Construir um perfil de aplicação quer dizer customizar esquemas de metadados, direcionando o padrão para uma aplicação específica (HEERY; PATEL, 2000).

Para customizar o DC, primeiramente dois estudos foram realizados: uma investigação sobre os principais perfis de aplicação atualmente usados para teses e dissertações e uma análise de como os itens são descritos nos repositórios das universidades prioritárias, em que seria feita a coleta das teses e dissertações pelo projeto. 
O estudo dos perfis de aplicação existentes para teses e dissertações envolveu: a análise de Alves e Café (2010) sobre o perfil de aplicação da Biblioteca Digital Brasileira de Teses e Dissertações/BDTD; o perfil Networked Digital Library of Theses and Dissertations/NDLTD (HICKEY; PAVANI; SULAMAN, 2010), criado para integrar mundialmente redes de bibliotecas de teses e dissertações; 0 estudo de Jones (2004) sobre os perfis de aplicação para teses e dissertações do software DSpace e da Universidade Virginia Tech; e a proposta de Qualificação de Dublin Core e sua evolução através do esquema DCTerms, desenvolvidas pela entidade que mantém o DC.

A customização do DC envolveu a escolha dos elementos de DC apropriados e a adequação de seu uso para descrever os itens da coleção TDM; a criação de novos elementos para atender as necessidades do projeto, a partir da qualificação de elementos de DC e a definição de regras e vocabulários controlados para a codificação dos valores dos metadados. 0 quadro 1 sintetiza 0 perfil de aplicação.

A figura 3 traz um exemplo com os metadados de um item para o usuário final, enquanto a figura 4 retrata um item na plataforma interna do projeto, o Omeka.

No Quadro 1 e nas figuras 3 e 4 pode-se observar que diferentes dados foram normatizados (título, autor, assunto, colaborador/ orientador, formato), controlados (instituição/editor, fonte/programa, tipo, idioma), atribuídos (tópico espacial IBGE, local de publicação IBGE, tópico temporal, notas) ou gerados (o detalhamento do tópico espacial em país, arco, estado, município e situação, sendo o caso e do local de publicação em país, arco, estado, município e situação, dependendo do local). Alguns dados são simplesmente copiados, sem intervenção dos coletores (dados brutos como descrição, data, identificador e direitos).

Cabe explicar no que consiste, por exemplo, a normatização dos nomes de autores. Não atribuímos autoria ou vinculamos as 


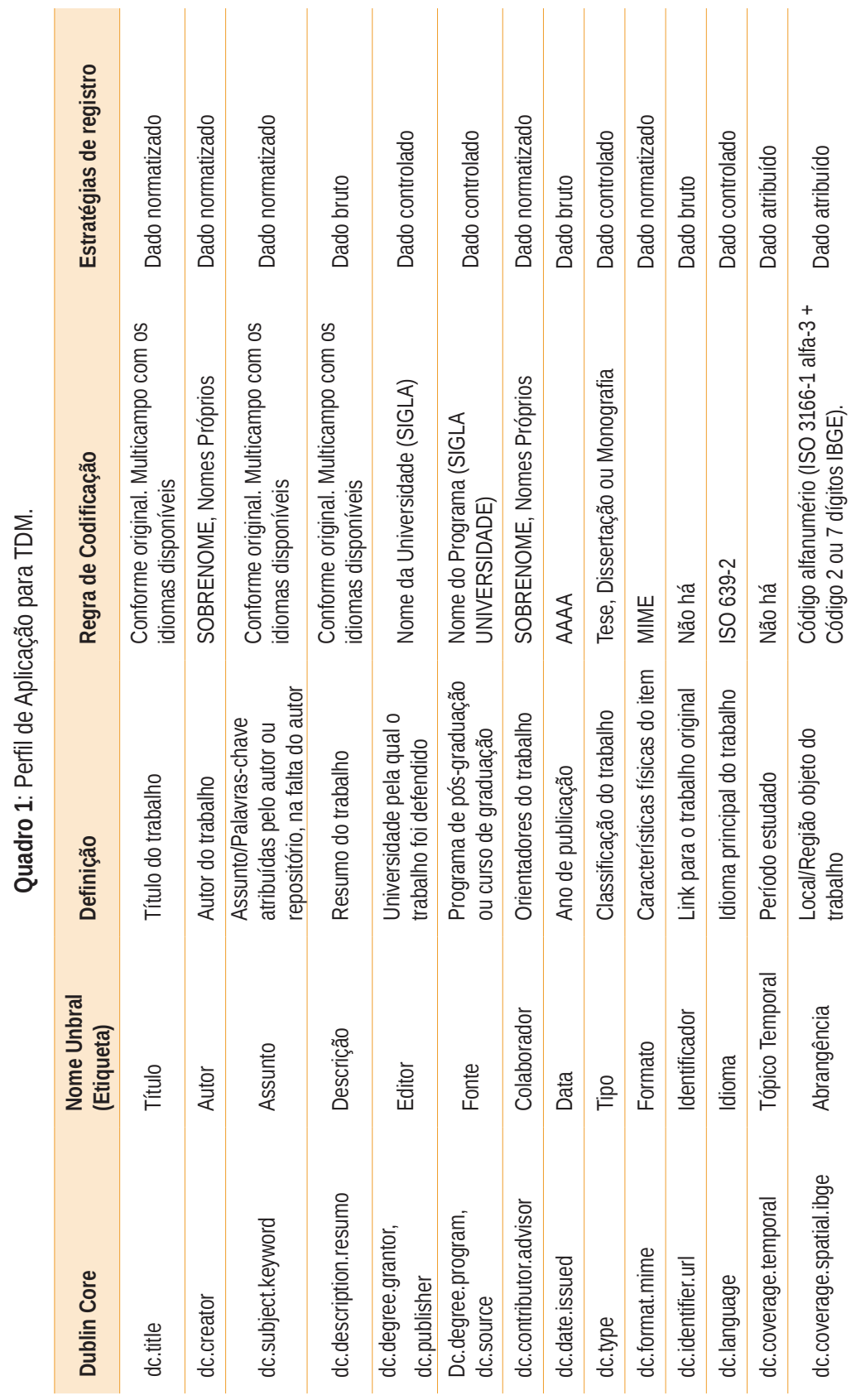




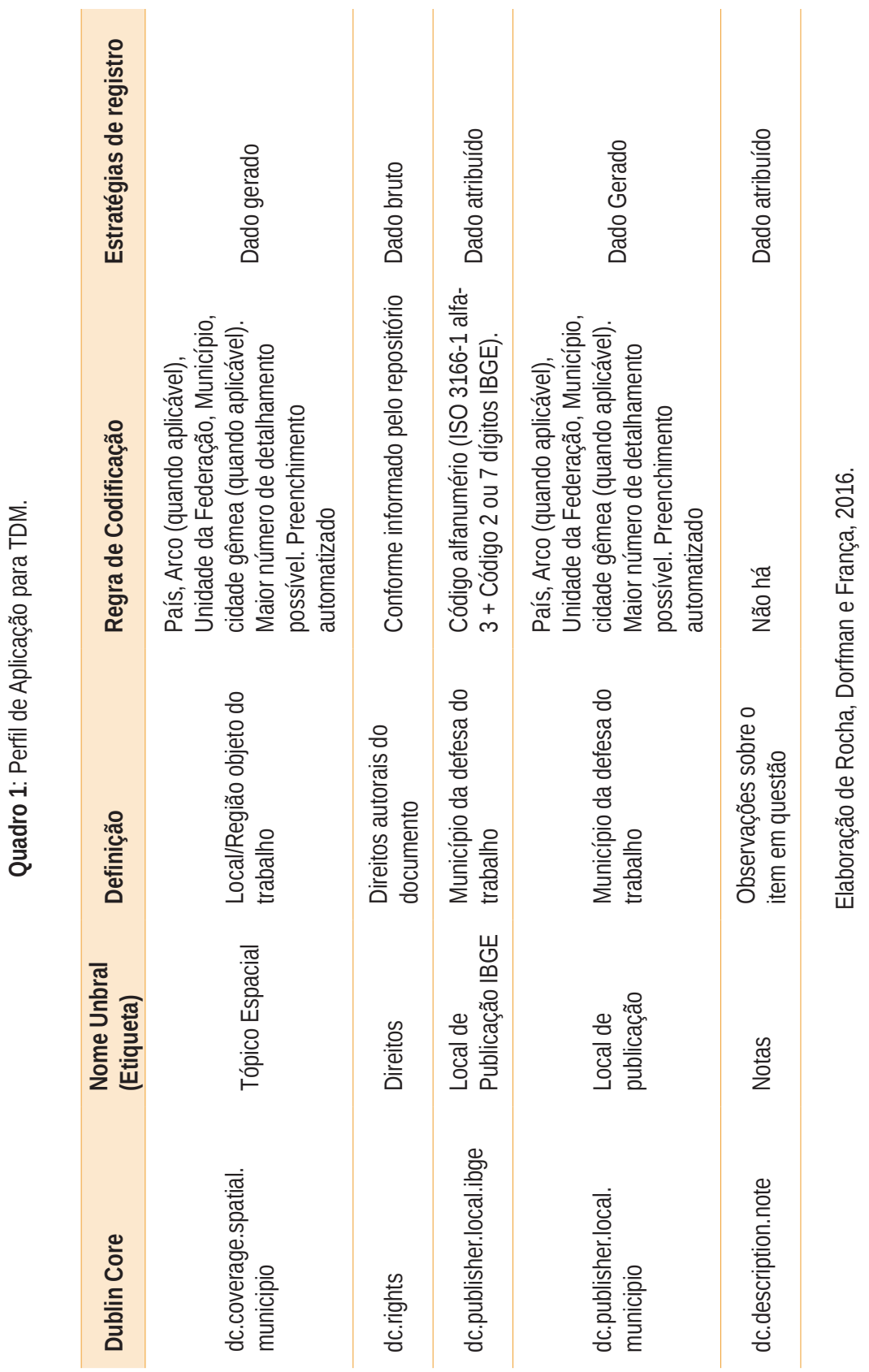




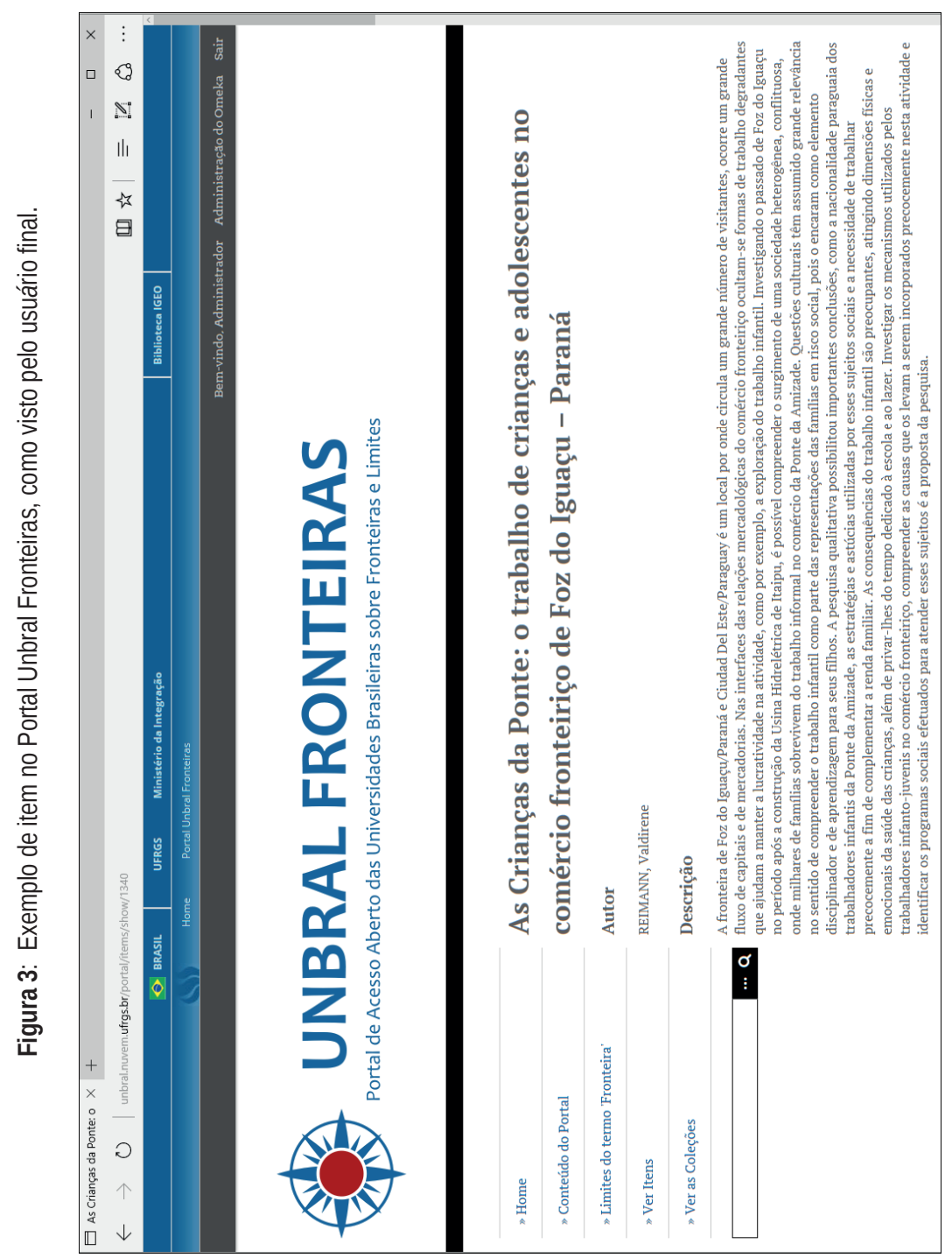

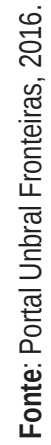


Anuário Unbral das Fronteiras Brasileiras 2015

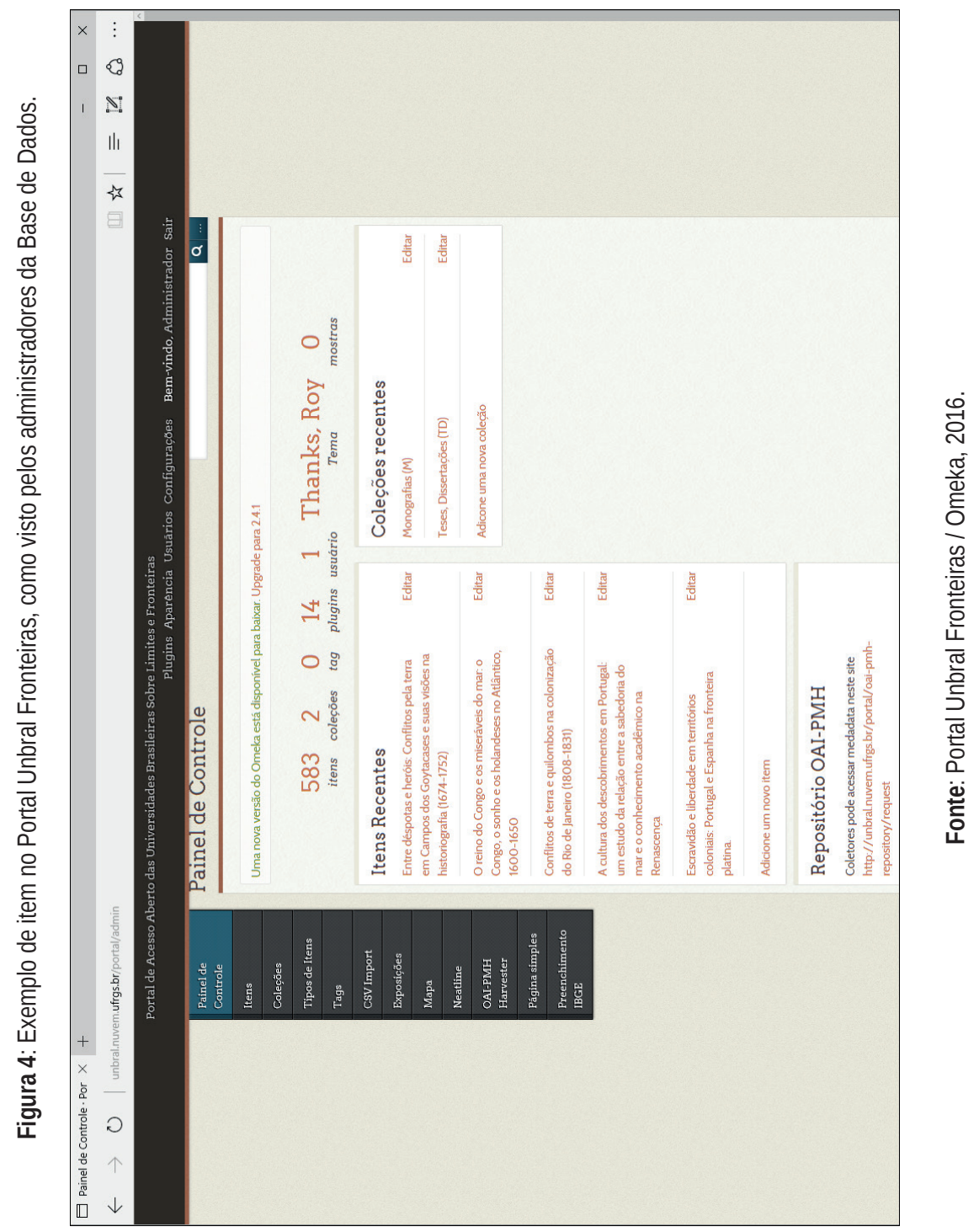


diferentes grafias ou formas através das quais um autor pode ser identificado, apenas convencionamos que a forma é SOBRENOME, Nomes Por Extenso.

Vocabulários controlados, tabelas e regras de codificação têm como objetivo um maior controle dos valores preenchidos. A consistência dos valores preenchidos facilita a indexação, recuperação e posterior interpretação da informação. Talvez, futuramente, graças ao acúmulo de ocorrências e recorrências, possamos propor um vocabulário controlado de nomes e assuntos. Talvez isso implique num apagamento de variações que podem ser significativas de transformações e tendências individuais ou da comunidade. $O$ dilema que se apresenta parece orbitar entre indexação e variabilidade, entre análises quantitativas e qualitativas.

Atenção especial foi dada para os descritores geográficos. No perfil de aplicação, foram usados os seguintes padrões para descritores geográficos.

\section{A EXPRESSÃO ESPACIAL DOS ITENS}

Georreferenciar bancos de dados permite análises de extremo interesse para os envolvidos em Estudos Fronteiriços, profissionais sensíveis aos processos espaciais. Assim, foi necessário criar campos no perfil de aplicação que permitam fácil expressão cartográfica. Isto foi definido em diálogo com o Heinrich Hasenack, geógrafo e professor no Instituto de Biociências da UFRGS, Porto Alegre, RS, com experiência em geoprocessamento, sendo posteriormente desenvolvido pelo colaborador Giovanne José Dalalibera.

A busca de um vocabulário controlado para lugares nos levou aos padrões propostos pelo Instituto Brasileiro de Geografia e Estatística (IBGE), adotados nacionalmente. O IBGE propõe códigos para as unidades da federação (UF, isto é, estados e distrito federal) com dois dígitos. Mais detalhados são os códigos 
para os municípios, com sete dígitos numéricos, em que os dois primeiros numerais representam a UF (IBGE, 2016).

No nosso caso, os códigos de município foram combinados com os códigos para país ISO 3166-1 alfa-3, com três letras, também adotados pelo IBGE. Como curiosidade, cabe citar que os códigos da norma ISO 3166-1 alfa-3 são hoje utilizados nos passaportes "inteligentes", aqueles dotados de identificação por radiofrequência (RFID) e lidos por máquinas. A lista completa de códigos ISO 3166-1 alfa-3 pode ser consultada como "Países e territórios - códigos e abreviações" (IBGE, 2016). Sua adaptação para uso no projeto Unbral Fronteiras está no Apêndice II - Tabelas de codificação para georreferenciamento, no fim deste Anuário.

Esses códigos facilitam a vinculação com arquivos shapefile, que permitem associar diferentes atributos de lugares, começando com posição e formato, adicionados, por exemplo, dos itens que catalogamos (ARCGIS, 2016). Assim, torna-se possível apresentar as consultas à base em formato cartográfico.

Os Estudos Fronteiriços brasileiros compartilham uma regionalização baseada na Proposta de Reestruturação do Programa de Desenvolvimento da Faixa de Fronteira (PDFF), de 2005. Este documento propõe que se entenda a fronteira brasileira com auxílio dos conceitos de faixa de fronteira, arcos de fronteira, cidades-gêmeas, cidades na fronteira, cidades na faixa de fronteira.

Segundo o PDFF, a faixa de fronteira é a área compreendida entre o limite interestatal continental e uma linha paralela a este, a $150 \mathrm{~km}$. A faixa de fronteira respeita os limites municipais, de modo a incluir o território dos municípios fronteiriços integralmente na faixa (BRASIL, 2005, p. 9).

Sobre os arcos de fronteira, lemos no PDFF que estudos apontam para a macrodivisão da faixa de fronteira em três grandes Arcos. O primeiro é o Arco Norte, compreendendo a faixa de fronteira dos estados do Amapá, Pará, Amazonas e os estados de Roraima 
e Acre (totalmente situados na faixa de fronteira). O segundo é o Arco Central, que compreende a faixa de fronteira dos estados de Rondônia, Mato Grosso e Mato Grosso do Sul. O terceiro é o Arco Sul, que inclui a fronteira dos estados do Paraná, Santa Catarina e Rio Grande do Sul (BRASIL, 2005, p.52).

As cidades na fronteira, isto é, as sedes dos 588 municípios na faixa de fronteira, são também classificadas no PDFF, conforme segue

Grosso modo podem ser classificados em dois grandes grupos, os lindeiros e os não-lindeiros. No grupo dos municípios lindeiros existem três casos:

- $\quad$ aqueles em que o território do município faz limite com o país vizinho e sua sede se localiza no limite internacional, podendo ou não apresentar uma conurbação ou semiconurbação com uma localidade do país vizinho (cidades-gêmeas);

- $\quad$ aqueles cujo território faz divisa com o país vizinho, mas cuja sede não se situa no limite internacional; e

- $\quad$ aqueles cujo território faz divisa com o país vizinho, mas cuja sede está fora da Faixa de Fronteira.

O grupo dos municípios não-lindeiros, ou seja, na retaguarda da faixa pode ser dividido em dois subgrupos:

- $\quad$ aqueles com sede na Faixa de Fronteira; e

- $\quad$ aqueles com sede fora da Faixa de Fronteira. (2005, p.11).

A classificação das cidades na fronteira adotada consta na "Lista dos Municípios pertencentes a Faixa de Fronteira (CDIF, 2016)". No apêndice II tal classificação integra a tabela de codificação para georreferenciamento.

Toda a regionalização da fronteira brasileira pode ser associada aos códigos ISO 3166-1 alfa-3 + IBGE, através da construção de tabelas de correspondência, como mostra a figura 5 , a seguir.

Duas são as informações espaciais presentes na ficha de catalogação dos itens. A primeira informação é o local de publicação, 


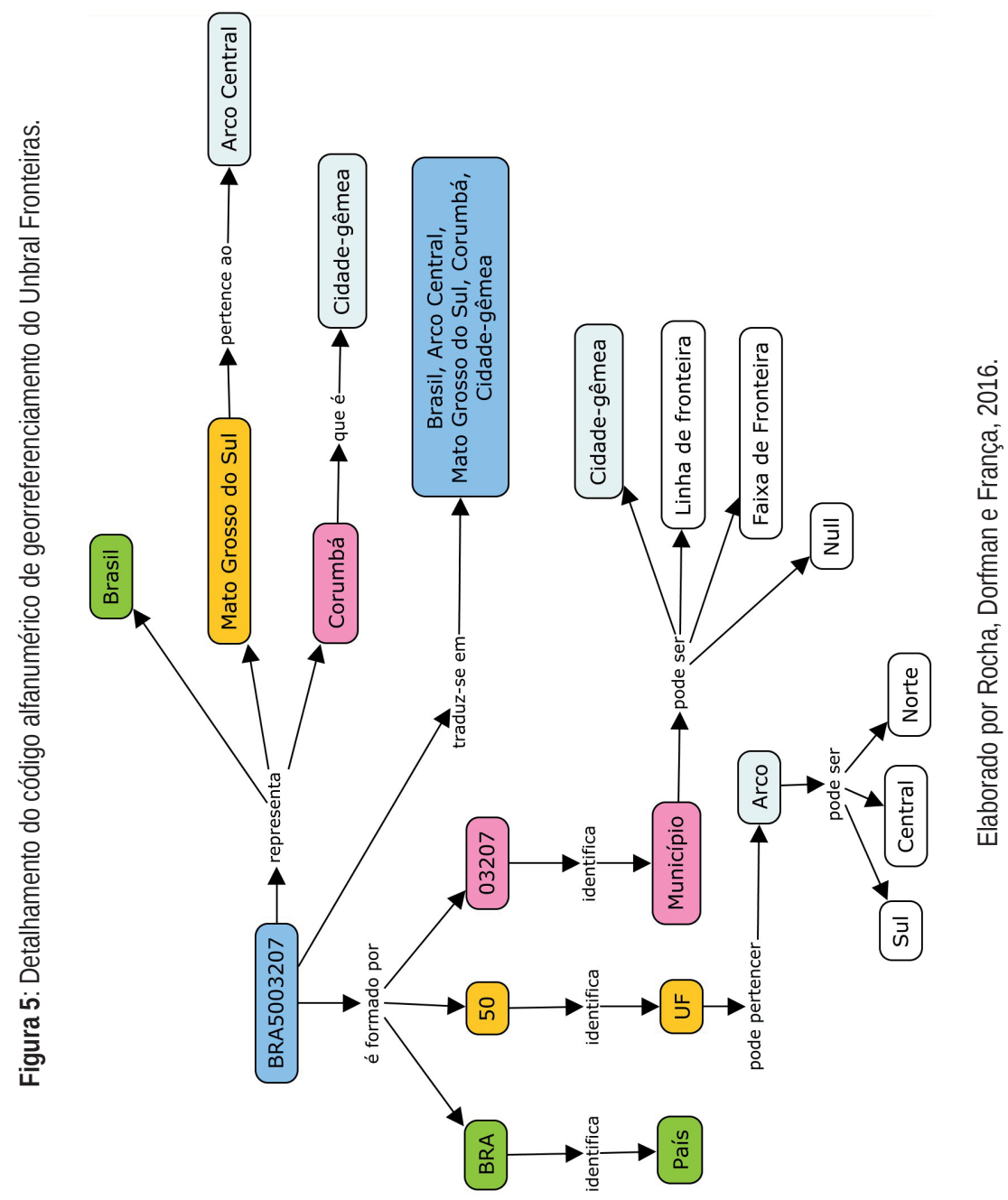


isto é, o dado sobre onde foi produzido o item. Na base de dados, essa informação aparece duas vezes: como "local de publicação IBGE", em que o município em que se encontra a instituição produtora do estudo recebe o código IBGE correspondente, acrescido dos códigos ISO 3166-1 alfa-3; e como "local de publicação", isto é, analisando 0 código atribuído e explicitando o país, 0 arco (sendo 0 caso), o estado, o município e sua situação relativa à fronteira (sendo o caso). Na coleção TDM, o "local de publicação" é o município em que se encontra o programa de pós-gradução em que foi defendida a monografia, dissertação ou tese. Em coleções que venham a ser processadas no futuro, o "local de publicação" será a cidade da editora do artigo, livro etc. Essa informação é obtida no item original.

A segunda informação espacial presente no perfil de aplicação descreve os lugares tematizados nos textos catalogados. Essa informação também aparece duas vezes, sendo a primeira identificada como Abrangência (em que se utiliza o código ISO 3166-1 alfa-3 + IBGE) e a segunda como Tópico Espacial (em que o código aparece de forma textual). Essa informação é atribuída pelo catalogador a partir da leitura do item sob catalogação. Assim, a produção de cada fichamento reveste-se de caráter qualitativo, especializado, limitando as possibilidades de coleta automática (harvesting).

Lembremos tratar-se de trabalhos sobre a fronteira, o que faz com que muitas vezes haja referência aos fenômenos que se dão fora do território brasileiro, fora das tabelas do IBGE. Infelizmente, não temos (conhecimento) de uma grade unificada, na escala local (de municípios ou equivalentes) para os países fronteiriços. Nesses casos, o catalogador lista as regiões citadas e classifica os países com base no código ISO 3166-1 alfa-3. Ao mesmo tempo, o catalogador elabora uma lista de recortes internacionais citados nos trabalhos, tais como Área de Livre Comércio das Américas (ALCA), Cone Sul, Mercado Comum do Sul (MERCOSUL), Amazônia Legal etc. informando o que eles representam. Por exemplo, North American Free Trade Agreement (NAFTA) inclui Canadá, México 
e Estados Unidos, o que é representado como CAN, MEX, USA.

Todos esses esforços voltam-se a construir uma base de interesse para a comunidade dos Estudos Fronteiriços, consultando e reforçando esquemas de interpretação já utilizados pelos pesquisadores.

\section{INDEXANDO PERÍODOS HISTÓRICOS}

Entre os metadados coletados, incluímos o "tópico temporal", a partir de troca de ideias em torno do tema com o Dr. Tiago Gil, coordenador do Atlas Digital da América Lusa (ATLAS, 2016). A sugestão do especialista foi deixar esse campo para preenchimento ad hoc, uma vez que não há vocabulário controlado para períodos históricos, e mesmo não parece ser desejável que haja.

\section{A COLETA DOS DADOS}

A coleta envolve trazer para BD Unbral Fronteiras a descrição dos registros de TDM que estão nas bases de dados fontes, representando esses registro na coleção TDM, de acordo com o perfil de aplicação (representado no quadro1). A coleta é uma atividade periódica, isto é, é executada com uma frequência prédeterminada em cada base de dados fonte, a fim de que suas atualizações sejam refletidas na BD TDM. A coleta das informações em cada fonte seguiu a seguinte estratégia:

1. Seleção dos itens, através do uso de expressões de busca que contém termos relacionados à fronteira, como: fronteira, fronteirização, fronteiridades, fronteiriço, fronteiriça, transfronteiriço, transfronteiriça, com o uso de recursos de truncagem (front\$, front* etc.), se presente na base de dados consultada

2. Identificação dos itens pertinentes, em termos temáticos, entre aqueles selecionados 
3. Representação dos itens pertinentes em planilha, envolvendo:

- A uniformização dos nomes dos autores (campos Autor e Colaborador)

- A uniformização dos nomes das Instituições de origem (campo Editor) e dos programas (campo Fonte)

- Correção das palavras chaves (campo Assunto)

- Descrição do tópico temporal (campo Tópico Temporal)

- Descrição geográfica para o tópico espacial (campo Tópico Espacial IBGE) e para a instituição de origem (campo Editor)

4. Revisão dos dados

5. Importação dos dados no OMEKA

6. Geração automática dos campos Tópico Espacial e Local de Publicação

7. Publicação dos registros

\section{O REPOSITÓRIO DE DADOS}

O software OMEKA foi escolhido para implementar o repositório hospedeiro da base de dados de TDM. Esse software permite a criação de várias coleções, e os itens dessas coleções são descritos em Dublin Core. Além dos metadados de Dublin Core, Omeka também permite a inclusão de novos elementos. Isso é feito através do recurso denominado Tipo de Item (Item Types).

No OMEKA, o Tipo de Item TDM foi criado para representar as TDM. Um item do tipo TDM contém os elementos de Dublin Core adicionados de outros novos elementos. Na tabela 1 já mostramos como os elementos do Perfil de Aplicação de TDM são codificados no OMEKA

No perfil de aplicação, o tópico espacial (abrangência) e o local de publicação são georreferenciados, em nível máximo de município. 
Para representar o município, foi adotada uma codificação composta pelo código do país, seguida da codificação para municípios do país, conforme detalhado na seção A Expressão Espacial dos Itens. No caso do Brasil, a tabela do IBGE para municípios foi adotada. A adoção da tabela do IBGE para municípios traz facilidades para o georreferenciamento, visto que existem disponíveis vários mapas cujos municípios são georreferenciados e identificados pelo código do IBGE. No perfil de aplicação, a representação codificada para município é usada nos elementos Abrangência e Local de Publicação-IBGE.

O uso de representação codificada não é ideal para busca textual, pois requer do usuário o conhecimento do código. Para permitir a recuperação do item via busca textual, isto é, usando os nomes dos locais de abrangência e de publicação, os elementos Local de Publicação e Tópico Espacial foram especificados no perfil de aplicação. Esses elementos contêm valores textuais equivalentes para os códigos registrados nos elementos Abrangência e Local de Publicação-IBGE, respectivamente. Esses valores textuais são estruturados da seguinte forma: País, Arco, Estado, Município, Característica.

Os valores de Local de Publicação e Tópico Espacial são gerados automaticamente a partir dos códigos representados nos campos Abrangência e Local de Publicação-IBGE, respectivamente. Por exemplo, em um item que contém o valor BRA4317103 para 0 elemento Abrangência, o valor para do elemento Tópico Espacial gerado a partir desse código é: Brasil, Arco Sul, Rio Grande do Sul, Sant'Ana do Livramento, cidade-gêmea.

A geração dos valores textuais a partir dos valores codificados foi realizada através do uso das seguintes tabelas de correlação, mostradas no quadro 2, ao lado.

A geração dos valores para os campos Local de Publicação e Tópico Espacial foi implementada no Omeka através do recurso chamado de Omeka Plugln. Esse recurso permite a construção 
Quadro 2: Tabelas de correlação para o georreferenciamento, suas fontes e estrutura dos seus dados no repositório Omeka do Unbral Fronteiras.

\begin{tabular}{|c|c|c|}
\hline Tabela & Fonte & Estrutura \\
\hline Países & IBGE Países e Territórios & $\begin{array}{l}\text { código do país, } \\
\text { nome do país }\end{array}$ \\
\hline Estados & $\begin{array}{l}\text { IBGE Municípios } \\
\text { IBGE Países e Territórios, } \\
\text { PDFF } 2005 \text { (Arcos) }\end{array}$ & $\begin{array}{l}\text { código do país, } \\
\text { código do estado, } \\
\text { nome do estado, } \\
\text { sigla do estado, } \\
\text { nome do arco do estado }\end{array}$ \\
\hline Municípios & $\begin{array}{l}\text { IBGE Municípios, } \\
\text { Lista de Municípios Pertencentes } \\
\text { a FF }\end{array}$ & $\begin{array}{l}\text { código do município, } \\
\text { código do estado, } \\
\text { nome do município, } \\
\text { classificação do município }\end{array}$ \\
\hline
\end{tabular}

Elaboração de Rocha, Dorfman e França, 2016.

(implementação) de novos módulos para o Omeka. Para o projeto Unbral, foi desenvolvido o Plugln Preenchimento IBGE pelo colaborador Giovanni Delalibera.

\section{O PLUGIN "PREENCHIMENTO IBGE"}

O Plugln Preenchimento IBGE permite a geração de campos com valores textuais a partir de campos com códigos, utilizando vocabulários controlados para nomes textuais equivalentes. Ele gerencia a redundância da informação, visto que permite a manutenção da correlação dos valores dos campos com códigos (como Local de Publicação IBGE) com os valores dos campos textuais equivalentes (como Local de Publicação). Por exemplo, sempre que houver alteração em um valor de Local de Publicação IBGE, o plugin permite a atualização do valor textual no elemento Local de Publicação equivalente. 
Além disso, ele também gera alertas para possíveis preenchimentos incorretos para os campos com códigos (Abrangência e Local de Publicação-IBGE), permitindo a correção em lote dos campos com códigos incorretos (Abrangência e Local de Publicação-IBGE). Automaticamente, ele permite a geração em lote dos campos textuais, agilizando a produção.

O plugin foi implementado em PHP com a extensão das bibliotecas de Plugln do OMEKA, e a adição na base de dado MySQL das tabelas que mapeiam códigos para valores textuais.

\section{O TRABALHO COLABORATIVO NO APOIO AO DESENVOLVIMENTO DA BASE DE DADOS}

O desenvolvimento e a manutenção da base de dados de TDM envolve uma equipe multidisciplinar e situada em diferentes locais (instituições parceiras). Na fase de desenvolvimento, essa equipe participa coletivamente de atividades como a identificação das fontes de coleta, a especificação das tarefas de coleta, a elaboração da estrutura para representar na base de dados os registros coletados (esquema de metadados), a implantação e customização do software da base de dados, entre outras. A fase de manutenção da base de dados compreende realizar a coleta continuada dos registros nas diversas fontes.

Muitas das atividades do desenvolvimento da base de dados são permanentes, isto é, continuam ocorrendo após a sua construção, junto com a fase de manutenção. Por exemplo, a especificação das tarefas de coleta é uma atividade contínua, em que novas técnicas e recomendações de coleta são adicionadas sempre que ocorrerem novos aprendizados ou surgirem novas fontes de coleta.

Objetivando a realização das atividades de desenvolvimento e manutenção da base de dados, as tarefas referentes a essas atividades devem ser bem documentadas, e o uso e manutenção 
dessa documentação deve ser uma prática corrente da equipe. Para viabilizar isso, a documentação das tarefas deve estar disponível a toda equipe, via web, de forma centralizada, atualizada, e com controle de alterações, evitando a propagação e uso de versões antigas e não autorizadas. A execução dessas tarefas deve ser acompanhada pelos responsáveis pela gestão do projeto (e isso é viabilizado pelo registro de andamento), e os produtos resultantes dessas execuções devem ser identificados e registrados.

O desenvolvimento e a manutenção da base de dados de TDM são caracterizados como trabalho colaborativo, e ferramentas informatizadas podem contribuir significativamente no apoio a esse tipo de trabalho. Esse trabalho colaborativo envolve a especificação, a execução e o acompanhamento das atividades do projeto, e das tarefas especificadas nessas atividades. Também envolve a produção dos recursos definidos pelas tarefas (produtos do projeto).

O projeto optou pela adoção de uma ferramenta informatizada de apoio ao trabalho colaborativo para dar suporte ao desenvolvimento e à manutenção da base de dados de TDM, assim como para outras atividades, como elaboração dos anuários. A escolha e a configuração do ambiente informatizado para apoio ao trabalho colaborativo observou o modelo 3C (FUKS; RAPOSO; GEROSA, 2003). Segundo esse modelo de trabalho colaborativo, a colaboração é a combinação de cooperação, comunicação e coordenação:

Para colaborar, os indivíduos têm que trocar informações (se comunicar), organizar -se (se coordenar) e operar em conjunto num espaço compartilhado (cooperar). As trocas ocorridas durante a comunicação geram compromissos que são gerenciados pela coordenação, que por sua vez organiza e dispõe as tarefas que são executadas na cooperação. Ao cooperar os indivíduos têm necessidade de se comunicar para renegociar e para tomar decisões sobre situações não previstas inicialmente. Isto mostra 0 aspecto cíclico da colaboração. (FUKS; RAPOSO; GEROSA, 2003, p.10). 
Sob olhar do modelo 3C, em um ambiente informatizado de apoio ao trabalho cooperativo, a comunicação é atendida por sistemas de comunicação síncronos (como bate-papo) e assíncronos (como correio eletrônico e fóruns de discussão); a cooperação é atendida, por exemplo, por ambientes de escrita colaborativa; e a coordenação é contemplada por ferramentas de controle de fluxo, entre outras.

A ferramenta MediaWiki foi adotada para dar apoio ao trabalho colaborativo do projeto. MediaWiki também é a ferramenta utilizada para a construção colaborativa da Wikipedia. Tem como foco principal 0 desenvolvimento de texto colaborativo (cooperação). Permite que várias pessoas editem textos em conjunto (páginas wiki), e a organização desses textos segue a forma de hiperdocumento. Mantém o registro de todas as versões de cada documento, indicando a data e a pessoa que realizou cada contribuição. Para fomentar a discussão, permite a criação de um fórum de discussão para cada texto editado (comunicação), possibilita o estabelecimento de moderadores para as páginas (coordenação), assim como a categorização das páginas.

Os principais motivos que levaram à escolha da MediaWiki foram sua simplicidade, seu foco na escrita colaborativa, sua capacidade de permitir a organização dos documentos na forma hipertextual e de registrar o histórico das alterações no texto; além do fato que já ser uma ferramenta conhecida em função de seu uso pela Wikipédia.

No Unbral Fronteiras, o MediaWiki é usado como repositório dos documentos que registram atividades e tarefas desenvolvidas pelo projeto, assim como dos resultados e dos estudos realizados através destas. Esses documentos são editados por todos os membros do projeto (cooperação). O link "ver histórico" permite observar toda evolução dessa página, isto é, todas as suas versões, desde sua criação, indicando as pessoas que contribuíram na elaboração dessas versões. 
Os documentos são construídos de forma hipertextual, com uma organização que favorece a coordenação. No MediaWiki do Unbral Fronteiras, a página Atividades do Projeto é o ponto inicial da estrutura hipertextual que trata das atividades do projeto (coordenação) (figura 6). Nela são registradas as atividades do projeto, sua situação, assim as como tarefas realizadas nessas atividades e os produtos resultantes dessas tarefas. O histórico dessa página permite a verificação do estado de andamento das atividades do projeto em cada momento passado. As atividades, as tarefas e os produtos seguem uma estrutura hipertextual, cujas páginas são editadas coletivamente (cooperação).

Para facilitar a recuperação das tarefas, dos produtos e dos registros da execução das tarefas, páginas com essas três características são classificadas de acordo com as categorias: Tarefa, Produto e Gerenciamento. Por exemplo, Categoria:Tarefa lista as páginas que representam as tarefas do projeto, e Categoria:Gerenciamento lista as páginas que registram 0 andamento das atividades e das tarefas. A página Categoria:Produto lista os produtos (figura 7).

A página Esquema de Metadados para TDM é um exemplo de página que representa uma tarefa. Essa página representa a tarefa de elaboração do esquema para representar os registros bibliográficos das TDMs, que pertence a atividade "Base de Dados 2015-2016 - Teses Dissertações e Monografias". Nela são indicados dois produtos: um levantamento sobre esquemas existentes, que serviu de embasamento para a definição do esquema da TDM, e o esquema construído para a BD TDM (figura 8).

A página "Universidades Federais e seus repositórios" apresenta um produto da atividade "Base de Dados 2015-2016 - Teses Dissertações e Monografias", que contém o resultado do levantamento das instituições que contém repositórios com TDM que abordam 0 assunto fronteiras (figura 9). Esse documento é atualizado sempre que surgem novas instituições ou ocorrem 
Anuário Unbral das Fronteiras Brasileiras 2015

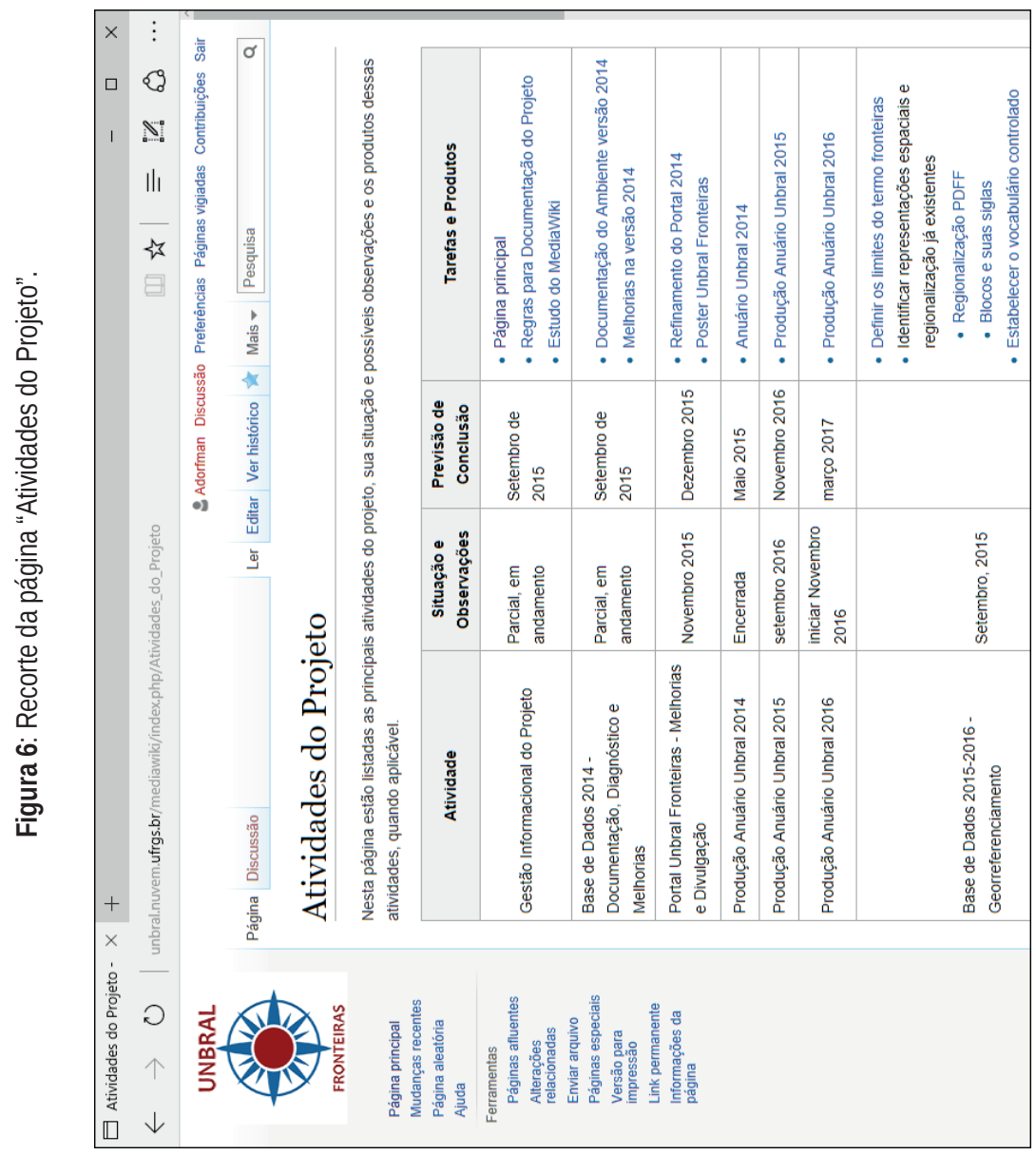

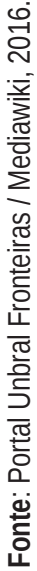


Anuário Unbral das Fronteiras Brasileiras 2015

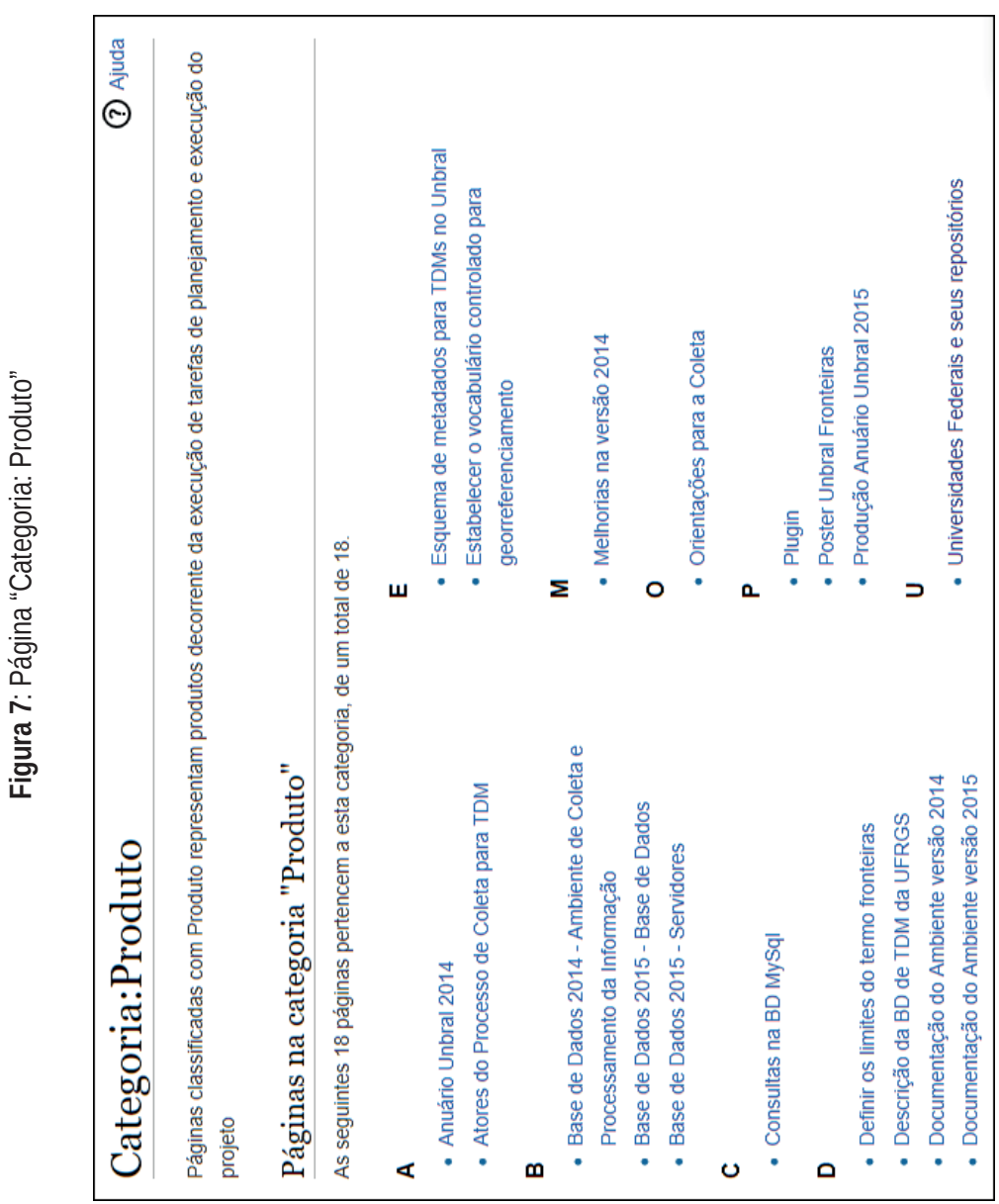

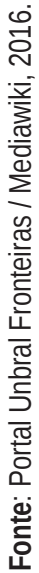


Anuário Unbral das Fronteiras Brasileiras 2015

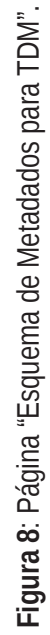

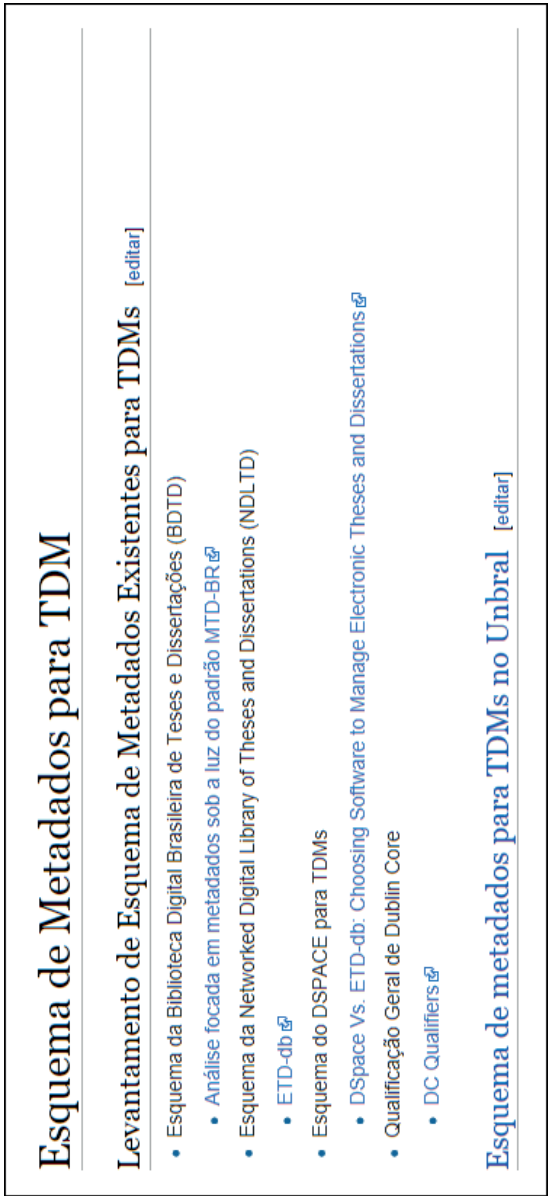

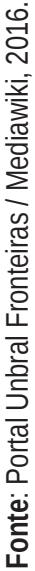


mudanças nas características das instituições já descritas.

O ambiente assume um papel importante no apoio à coleta dos dados nas diferentes fontes, que é realizado por equipes diversas. A coleta é uma atividade de manutenção, em que tarefas de coleta são definidas para cada instituição, isto é, são estabelecidos os passos para a realização da coleta em cada repositório fonte. Como a definição de cada tarefa é uma página Wiki, essa definição é alterada sempre que a equipe de coleta identificar mudanças na fonte ou encontrar formas mais aperfeiçoadas de coleta. Para coordenar o andamento da coleta, uma página wiki é criada para cada fonte de coleta. Páginas desse tipo registram quando foram realizadas as coletas, assim como observações pertinentes.

Por exemplo, a página Universidade Federal do Rio de Janeiro (UFRJ) trata da coleta no repositório da UFRJ (figura 10). O hiperdocumento que forma essa página possui ligações para diversas páginas, que indicam e registram a coleta, e documentam características dos repositórios. A estrutura de hiperdocumento é repetida para cada fonte de coleta.

No hiperdocumento de coleta da UFRJ, a página "Descrição da BD de TDM da UFRJ" contém a descrição das características do repositório da UFRJ (software usado, recursos de busca, estrutura dos registros, etc.) (figura 11). A página "Passo a passo da coleta nessa base (UFRJ)" representa a tarefa de coleta, cujo andamento da coleta é registrado em "Registros da Coleta da UFRJ". A página "Resultados da Coleta da UFRJ" identifica os registros de TDM coletados e inseridos na base de dados do Unbral (figura 12). A página "Orientações para a Coleta" apresenta recomendações para coleta que valem para qualquer fonte. Essa página faz parte dos hiperdocumentos de coleta de todas as fontes.

Em um ambiente de trabalho colaborativo, um fator importante para promover a colaboração é manter a equipe informada (comunicação) sobre quais foram as contribuições (cooperações) mais recentes. Dessa forma, todos da equipe passam a conhecer 


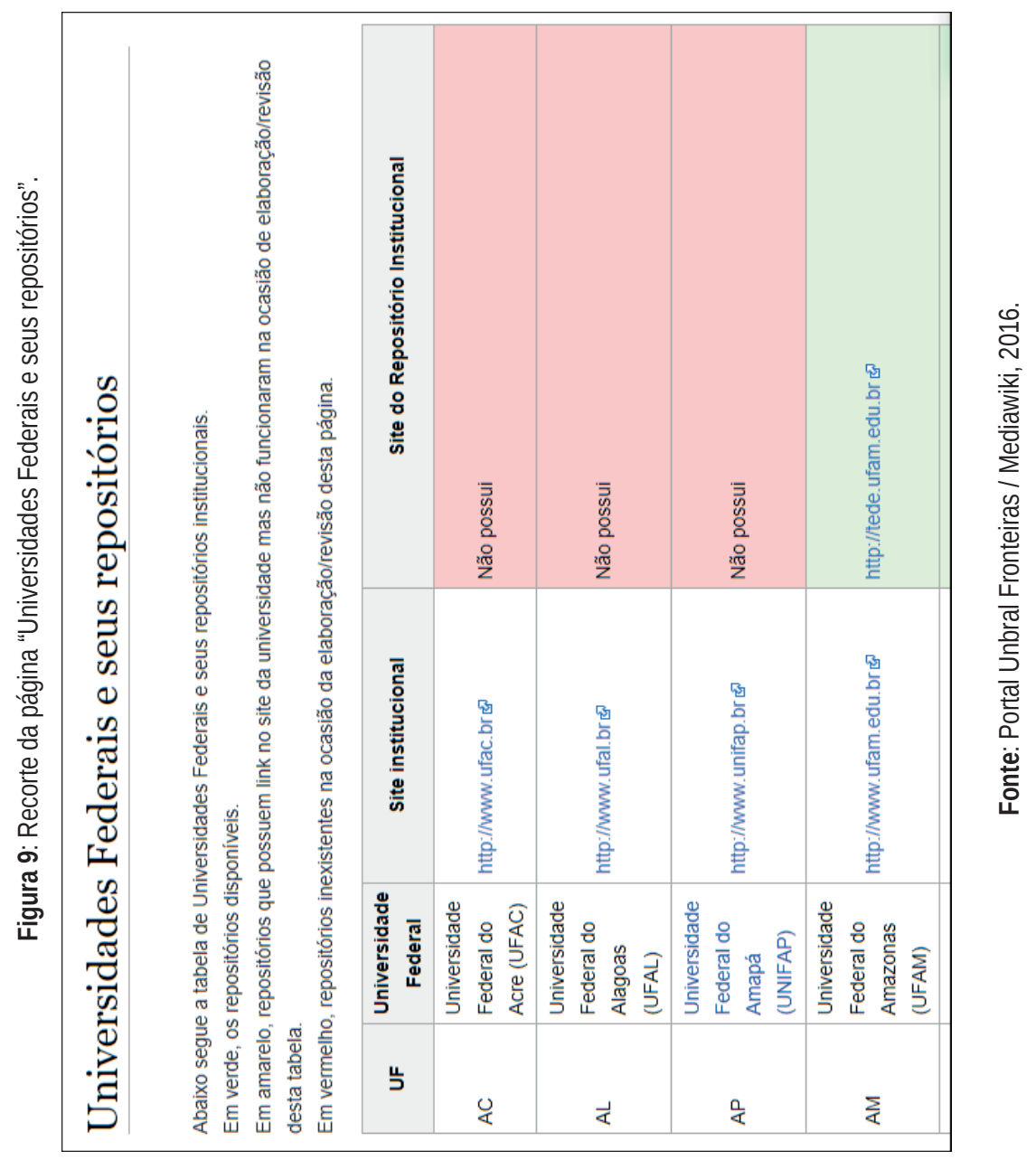


Anuário Unbral das Fronteiras Brasileiras 2015

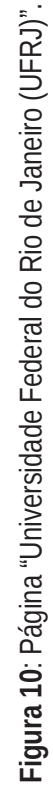

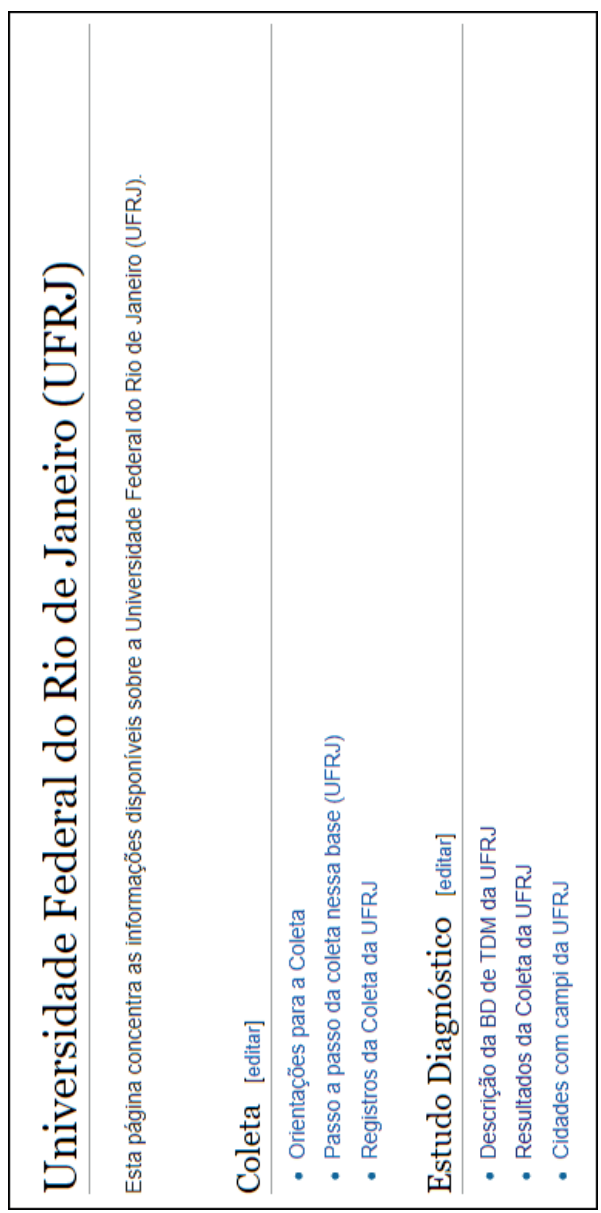

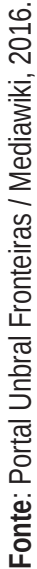




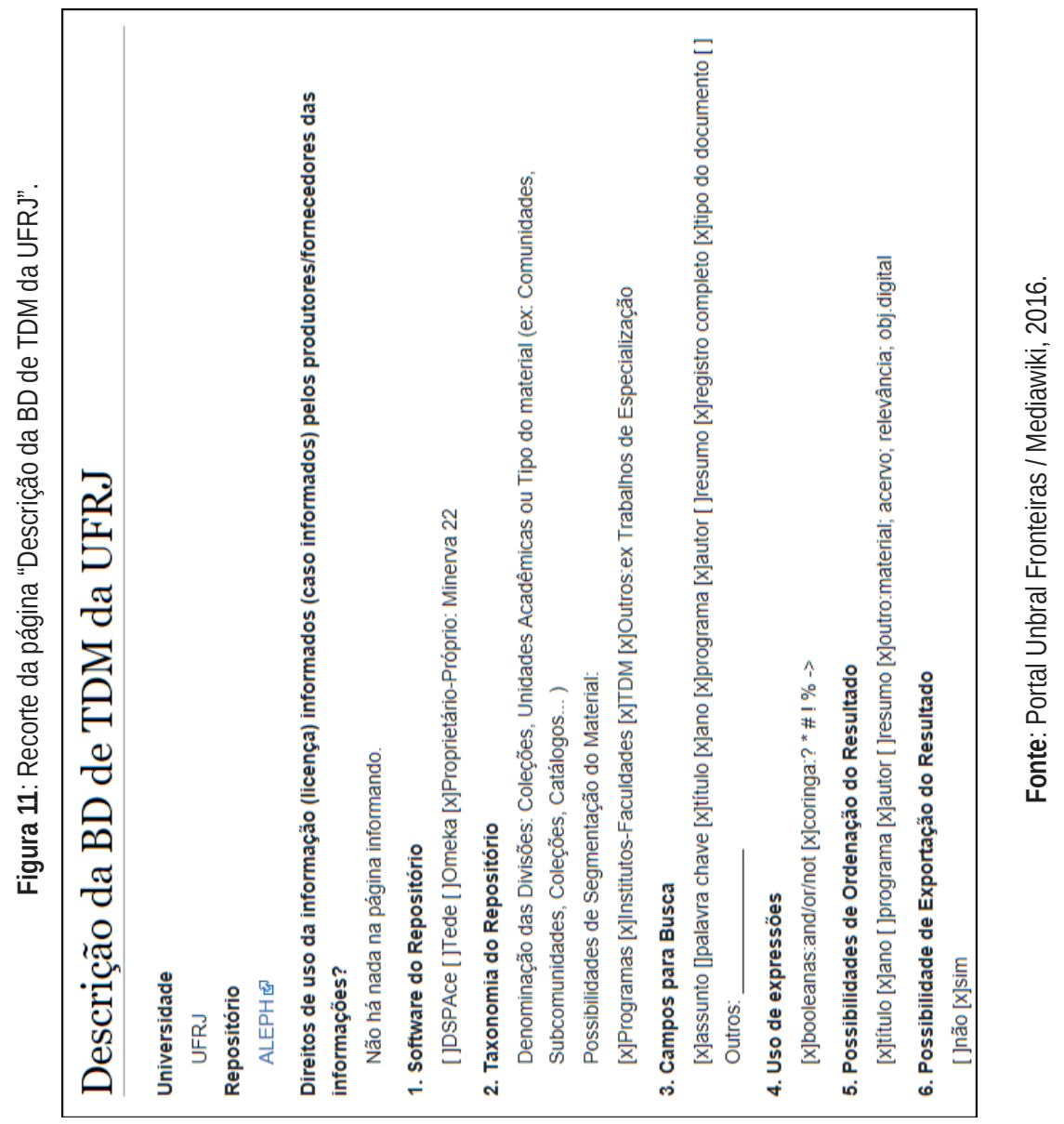




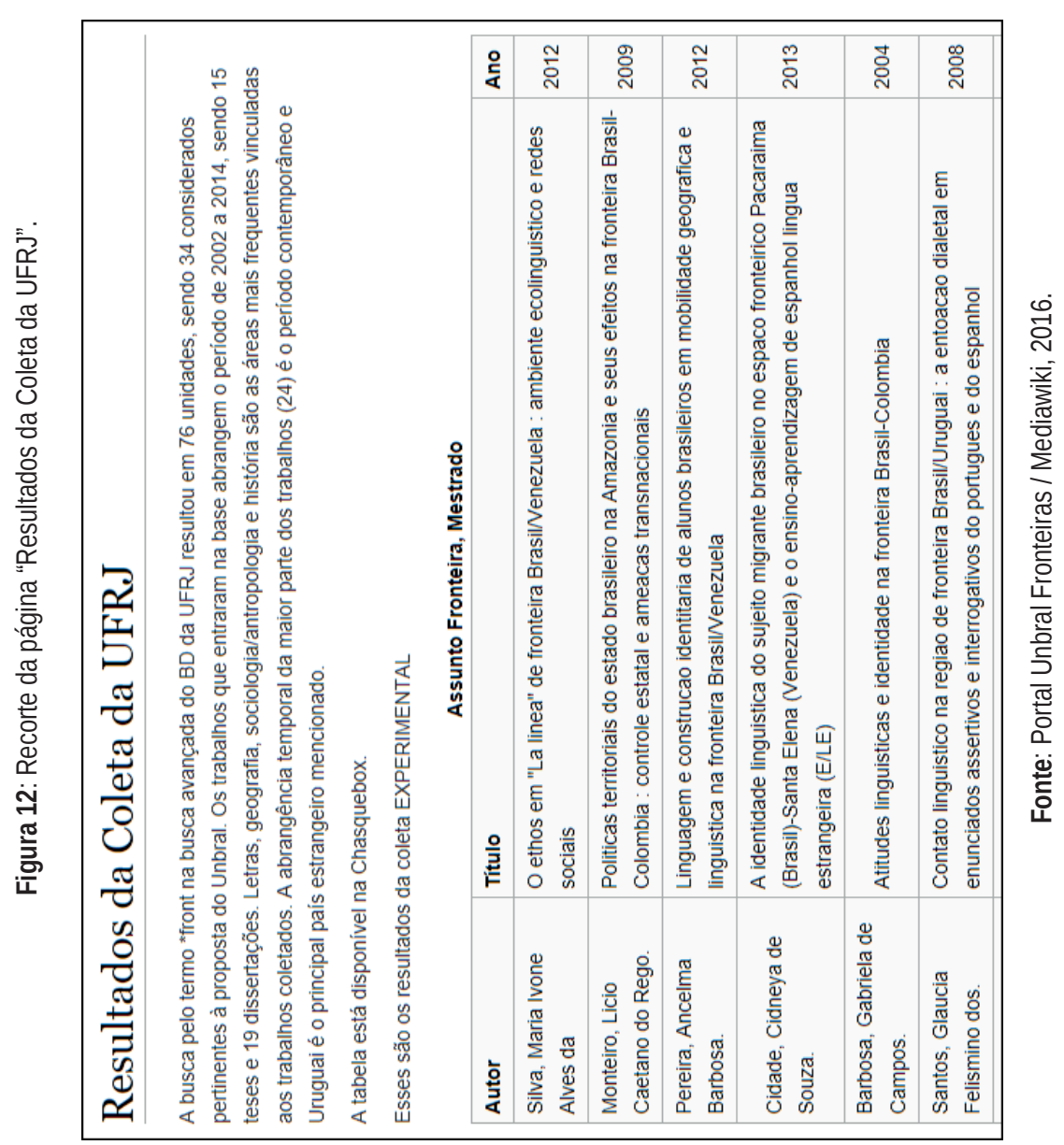


as mudanças e os rumos do projeto. Ao tomar conhecimento sobre uma determinada alteração, um membro do projeto pode apresentar também suas contribuições.

Para permitir que os membros do projeto Unbral Fronteiras se mantenham atualizados com relação ao seu andamento, a Página principal do projeto destaca (via link) a página Atividades do Projeto, que apresenta um panorama do projeto, relatando suas atividades (incluindo andamento), tarefas e produtos. Além disso, a página principal apresenta ligações para páginas especiais do MediaWiki que relatam as últimas alterações (incluindo os responsáveis pelas alterações), as páginas mais alteradas, e os usuários e suas contribuições (figura 6).

O uso do MediaWiki trouxe grande agilidade e organização ao projeto, tanto no que diz respeito ao seu gerenciamento, quanto no desenvolvimento dos seus produtos. Permite o registro, a construção e o acompanhamento centralizado das atividades, das tarefas e dos produtos do projeto, e possibilita que suas mudanças sejam realizadas de forma colaborativa, com a manutenção do histórico dos seus estados de desenvolvimento, e o registro das pessoas que contribuíram.

Ao observar o trabalho colaborativo sob as dimensões da comunicação, da coordenação e da cooperação, o ambiente possibilita que todos desenvolvam em conjunto as atividades, as tarefas e os produtos (cooperação), mantendo-se informados e discutindo sobre o que está sendo construído (comunicação), de uma forma organizada e com o registro de andamento e de colaborações (coordenação). Até o presente foram desenvolvidas 42 páginas, foram realizadas 1068 edições de páginas (contribuições), por nove colaboradores, como podemos observar na página Estatísticas.

Toda a estrutura e as ações do Projeto Unbral Fronteiras podem ser esquematizados na figura da próxima página (figura 13). 


\section{CONCLUSÕES}

Preencher bancos de dados (como o currículo Lattes e tantos outros cadastros) é uma das tarefas dos pesquisadores contemporâneos. Muitas vezes ficamos frustrados com a dificuldade em nos enquadrarmos nas classes oferecidas nos menus dropdown ou temos dificuldade em entender o que é solicitado. $O$ trabalho de pesquisa do Unbral Fronteiras aqui apresentado nos oferece um outro ponto de vista sobre o esforço necessário para criar descrições suficientes para os objetos concretos.

Ao encararmos essa tarefa tão especializada, ganhamos conhecimento sobre o potencial e as limitações de interpretações baseadas em bases de dados. Abrir essa caixa preta é indispensável diante da galopante digitalização do espaço, mais acirrado nas fronteiras interestatais. Já podemos afirmar que implementar uma base de dados requer profundo conhecimento do objeto concreto, valoriza o que melhor se enquadra, esconde o que não se encaixa.

A construção do Portal Unbral Fronteiras, em especial da coleção TDM, partiu da busca, realizada em diferentes repositórios, dos conteúdos a serem incluídos em nossa Base de Dados. Isto levou ao questionamento de como harmonizar metadados sistematizados de distintas formas, conforme escolhas institucionais. Fez-se, assim um minucioso levantamento de como as cinco fontes prioritárias catalogavam suas teses e dissertações. Esse estudo, que buscava convergências, apontou para a utilização do Dublin Core como esquema de metadados do Portal Unbral Fronteiras.

Para permitir georreferenciamento e manter a consistência do Portal, um sistema de codificação de georreferenciamento precisou ser construído. Isso quer dizer que as informações do campo "Abrangência" e "Local de Publicação" precisariam ter caráter de vocabulário controlado. Também era desejável que essa informação fosse cartografável de maneira relativamente simples.

Com essas demandas, chegou-se a um código alfanumérico 


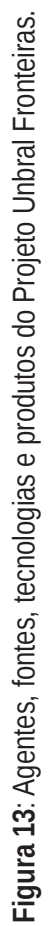

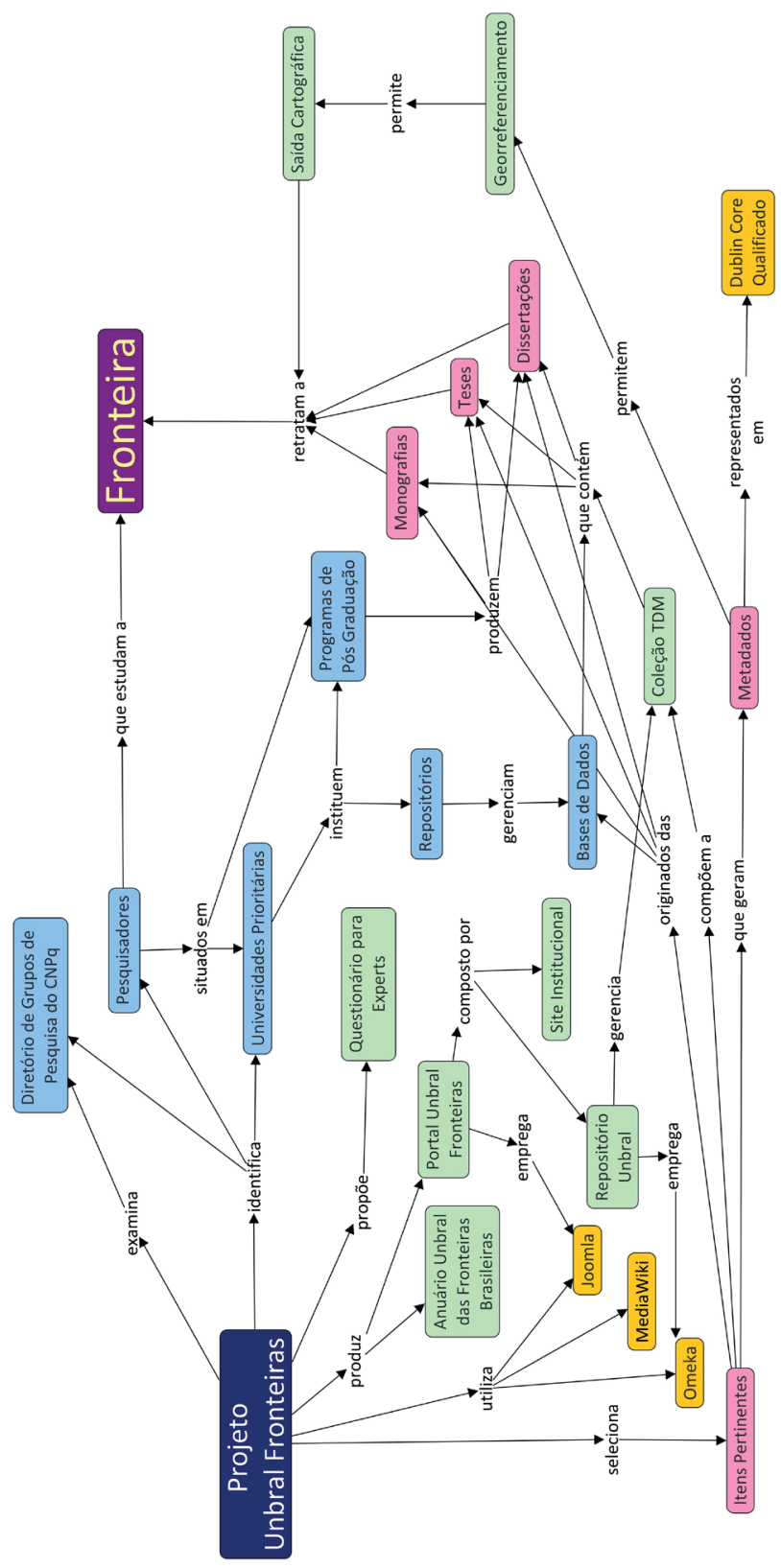

啇

苋

$\frac{\mathbb{0}}{\mathrm{C}}$

$\frac{9}{0}$

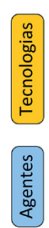

엉 
que é, na realidade, a junção de dois códigos já existentes. 0 primeiro, o código ISO 3166-1 alfa-3, um código de 3 letras que identifica os países existentes (utilizado pelas Nações Unidas e pelo IBGE), e o segundo, o código de 7 dígitos do IBGE que identifica UF e municípios brasileiros. A informação sempre é preenchida com o máximo de detalhamento disponível.

Ferramentas desenvolvidas pela equipe do Unbral Fronteiras são, assim, capazes de ler este código e produzir uma saída cartográfica apropriada. Textualmente, em metadados complementares, o código é traduzido, com o máximo de nível de detalhe possível e ainda com a informação sobre o arco de fronteira correspondente e se o município em questão é uma cidade-gêmea ou não. Nosso projeto se dedica, nesse momento, à construção de saídas cartográficas.

O triunfo das estratégias de catalogação e georreferenciamento não seria possível se o Unbral Fronteiras não se apoiasse no processo colaborativo e na interdisciplinaridade. A junção de geógrafos, comunicólogos e cientistas da informação possibilita que o projeto se proponha a responder e propor demandas complexas que seriam impraticáveis em outro contexto.

O georreferenciamento, que demandou grande energia e discussão, é uma das principais contribuições do Unbral Fronteiras. Além de reunida e pesquisável, a produção dos Estudos Fronteiriços brasileiros, ao ser georreferenciada, permite saídas cartográficas que representam a fronteira, os pesquisadores e a produção acadêmica, permitindo debates concretos e ontológicos.

Esperamos que o Portal Unbral Fronteiras contribuía para a pesquisa sobre fronteiras e para a circulação e aprimoramento da mesma. Por fim, esperamos que a síntese permitida pela leitura geral do campo dos Estudos Fronteiriços, através do trabalho do Unbral Fronteiras, contribua para a formulação de políticas públicas e para uma gestação cidadã das fronteiras brasileiras e sul-americanas. 


\section{REFERÊNCIAS}

ALVES, Jaqueline Costa; CAFÉ, Lígia Maria Arruda. Análise focada em metadados sob a luz do padrão MTD-BR. Em Questão, v. 16, n. 2, 2010. Disponível em: <http://www.seer.ufrgs.br/EmQuestao/article/view/12930>. Acesso em 10 de Out 2016.

AMILHAT SZARY, Anne-Laure; GIRAUT, Fréderic. Borderities: the politics of contemporary mobile borders. Basingstoke: Palgrave Macmillan, 2015.

ARCGis. Shapefiles - Ajuda do ARCGis. Disponível em: <http://doc.arcgis. com/pt-br/arcgis-online/reference/shapefiles.htm> Acesso em 10 de Out 2016.

ATLAS Digital da América Lusa. Disponível em: <http://hs.unb.br/atlas/ In\%C3\%ADcio>. Acesso em 10 de Out 2016.

BRASIL. Ministério da Integração Nacional. Secretaria de Programas Regionais. Programa de Desenvolvimento da Faixa de Fronteira. Proposta de Reestruturação do Programa de Desenvolvimento da Faixa de Fronteira. Ministério da Integração Nacional, Secretaria de Programas Regionais, Programa de Desenvolvimento da Faixa de Fronteira - Brasília: Ministério da Integração Nacional, 2005. Disponível em: <http://www.retis.igeo.ufrj.br/wp-content/ uploads/2005-livro-PDFF.pdf>. Acesso em 10 de Out 2016.

CAPES. Plataforma Sucupira. Disponível em: <https://sucupira.capes.gov.br/ sucupira/>. Acesso em 10 de Out 2016.

CDIF. Dados e informações sobre a faixa de fronteira. Disponível em: <http:// cdif.blogspot.com.br/>. Acesso em 10 de Out 2016.

CNPq. Sobre a Plataforma Lattes. Disponível em: <http://lattes.cnpq.br/>. Acesso em 10 de Out 2016.

DORFMAN, Adriana; MONTE MEZZO, Vitor; FRANÇA, Arthur Luna Borba França. Circunscrição temática do Unbral Fronteiras a partir da análise do questionário para Experts em Estudos Fronteiriços. In: DORFMAN, A. (org.). Anuário Unbral das Fronteiras Brasileiras 2014. Porto Alegre: Letra1; Instituto de Geociências - UFRGS, 2015. Disponível em: <http://www.ufrgs.br/igeo/ig/ arquivo/Anuario_Unbral_WEB.pdf> Acesso em 10 de Out 2016.

DORFMAN, Adriana; FRANÇA, Arthur Borba Colen. Estudos Fronteiriços no Brasil: uma geografia da produção científica. In: SILVA, Augusto César Pinheiro da Geografia Política, Geopolítica e Gestão do Território: racionalidades e práticas em múltiplas escalas. Rio de Janeiro: Gramma, 2016, p. 65-83. 
FUKS, H.; RAPOSO, A.B.; GEROSA, M.A. Do Modelo de Colaboração 3C à Engenharia de Groupware, IX Simpósio Brasileiro de Sistemas Multimídia e Web - Webmidia 2003, Trilha especial de Trabalho Cooperativo Assistido por Computador, 03-06 de Nov 2003, Salvador-BA, p. 445-452 Disponível em: <ftp://ftp.inf.puc-rio.br/pub/docs/techreports/02_17_fuks. pdf>. Acesso em 10 de Out 2016.

HEERY, Rachel; PATEL, Manjula. Application profiles: mixing and matching metadata schemas. Ariadne, n. 25, 2000. Disponível em: <http://www.ariadne. ac.uk/issue25/app-profiles/>. Acesso em 10 de Out 2016.

IBGE. CONCLA. Classificações» por tema» tabelas de código de áreas» tabelas de códigos de áreas. 2016. Disponível em: <http://concla.ibge.gov.br/ classificacoes/por-tema/codigo-de-areas/codigo-de-areas.html>. Acesso em 10 de Out 2016.

JONES, Richard. DSpace vs. ETD-db: Choosing software to manage electronic theses and dissertations. Ariadne, n. 38, 2004. Disponível em: <http://www. ariadne.ac.uk/issue38/jones\#sthash.3IPocn6K.dpf>. Acesso em 10 de Out 2016.

HICKEY, Thom, PAVANI, Ana; SULEMAN, Hussein. ETD-MS v1.1: an Interoperability Metadata Standard for Electronic Theses and Dissertations, Networked Digital Library of Theses and Dissertations, 2010. Disponível em: <http://www.ndltd. org/standards/metadata>. Acesso em 10 de Out 2016.

MARCONDES, Carlos Henrique; SAYÃO, Luis Fernando. Documentos digitais e novas formas de cooperação entre sistemas de informação em C\&T. Ciência da Informação, Brasília, v. 31, n. 3, p. 42-54, 2002. Disponível em: <http:// www.scielo.br/scielo.php?script=sci_arttext\&pid=S0100-19652002000300005>. Acesso em 10 Out 2016.

NISO (National Information Standards Organization). Understanding metadata. National Information Standards, v. 20, 2004. Disponível em: <http://www. niso. org/publications/press/UnderstandingMetadata. pdf>. Acesso em 10 de Out 2016.

PORTAL Unbral Fronteiras. Limites do termo fronteira. Disponível em: <http:// unbral. nuvem. ufrgs. br/portal/limites-do-termo-fronteira>. Acesso em 10 de Out 2016.

WEIBEL, Stuart. Metadata: The Foundations of Resource Description. D-Lib Magazine, Julho 1995. Disponível em <http://www. dlib.org/dlib/July95/07weibel. html>. Acesso em 10 de Out 2016. 
